\title{
GALILEO PROBE MASS SPECTROMETER EXPERIMENT
}

\author{
H. B. NIEMANN, D. N. HARPOLD \\ NASA-Goddard Space Flight Center, Greenbelt, MD 20771, U.S.A. \\ S. K. ATREYA, G. R. CARIGNAN \\ University of Michigan, U.S.A. \\ D. M. HUNTEN \\ University of Arizona, Tucson, U.S.A.
}

and

T. C. OWEN

University of Hawaï, U.S.A.

\begin{abstract}
The Galileo Probe Mass Spectrometer (GPMS) is a Probe instrument designed to measure the chemical and isotopic composition including vertical variations of the constituents in the atmosphere of Jupiter. The measurement will be performed by in situ sampling of the ambient atmosphere in the pressure range from approximately 150 mbar to 20 bar. In addition batch sampling will be performed for noble gas composition measurement and isotopic ratio determination and for sensitivity enhancement of non-reactive trace gases.

The instrument consists of a gas sampling system which is connected to a quadrupole mass analyzer for molecular weight analysis. In addition two sample enrichment cells and one noble gas analysis cell are part of the sampling system. The mass range of the quadrupole analyzer is from 2 amu to $150 \mathrm{amu}$. The maximum dynamic range is $10^{8}$. The detector threshold ranges from $10 \mathrm{ppmv}$ for $\mathrm{H}_{2} \mathrm{O}$ to 1 ppbv for $\mathrm{Kr}$ and $\mathrm{Xe}$. It is dependent on instrument background and ambient gas composition because of spectral interference. The threshold values are lowered through sample enrichment by a factor of 100 to 500 for stable hydrocarbons and by a factor of 10 for noble gases. The gas sampling system and the mass analyzer are sealed and evacuated until the measurement sequence is initiated after the Probe enters into the atmosphere of Jupiter. The instrument weighs $13.2 \mathrm{~kg}$ and the average power consumption is $13 \mathrm{~W}$.

The instrument follows a sampling sequence of 8192 steps and a sampling rate of two steps per second. The measurement period lasts appropriately $60 \mathrm{~min}$ through the nominal pressure and altitude range.
\end{abstract}

\section{Table of Contents}

1. Goals and Capabilities

1.1. Introduction

1.2. Science Goals and GPMS Capabilities

1.3. Direct Investigations

1.4. The Use of Enrichment Cells 1.4.1. Noble Gases

1.5. Other Possibilities

1.5.1. Photochemistry, Lightning and Internal Heat

2. Instrument Description

2.1. Introduction

2.2. Sample Inlet and Enrichment System

2.3. Ion Source

2.4. Quadrupole Mass Analyzer

2.5. Pumping System 
2.6. Electronic System

2.7. Reliability and Redundancy

3. Laboratory Calibration of the Instrument

4. Expected Results and Measurement Accuracies

5. Sampling Sequence Summary

References

\section{Goals and Capabilities}

\subsection{INTRODUCTION}

The Voyager observations, complemented by ground-based measurements, have contributed immensely to our knowledge of the atmosphere of Jupiter. Despite this success, however, the inventory of known constituents in the atmosphere is severely limited, the gross composition still includes large statistical uncertainties in the mixing ratios of various species, and the noble gas abundances (with the exception of helium) are completely unknown. Isotopic ratios, which might harbor the secret of the origin, and to some extent, evolution of the atmosphere of Jupiter, are hardly measured at all - the only exceptions being certain isotopes of carbon and hydrogen.

It is already apparent from a few isolated measurements that the atmosphere does not fully mimic the solar ratios of the elements. For example, $\mathrm{C} / \mathrm{H}, \mathrm{O} / \mathrm{H}$, and $\mathrm{N} / \mathrm{H}$ (from $\mathrm{CH}_{4}, \mathrm{H}_{2} \mathrm{O}$, and $\mathrm{NH}_{3}$ measurements, respectively) all appear to be enhanced relative to solar by factors of $2-3$, whereas $\mathrm{He} / \mathrm{H}$ and $\mathrm{Ge} / \mathrm{H}$ apparently have sub-solar values (Noll et al., 1988; Gautier and Owen, 1989; Carlson et al., 1991). Both $\mathrm{NH}_{3}$ and $\mathrm{H}_{2} \mathrm{O}$ condense and form clouds in the region of the atmosphere probed by Earth-based observations, so their absolute abundances are model-dependent. The situation becomes still worse for sulfur, which must be present but has not yet been detected, presumably because of its incorporation into $\mathrm{NH}_{4} \mathrm{SH}$ clouds (Weidenschilling and Lewis, 1973; Larson et al., 1984; Atreya and Romain, 1985). The current upper limit is $10^{-3}$ of the solar value.

Altitude-dependent mixing ratios are also exhibited by the disequilibrium species: those formed through photolysis and charged particle bombardment of various constituents in the upper atmosphere, others that are created by lightning discharges within the clouds, and a third set consisting of molecules formed under thermoequilibrium conditions at the high temperatures existing at great depths in the atmosphere, some of which are brought up to altitudes where we can observe them by strong vertical convection.

With in situ measurements, the Galileo Probe Mass Spectrometer (GPMS) is in a position to fill the gaps in our knowledge of the composition of the atmosphere of Jupiter. Furthermore, sample enrichment provides an opportunity to address fundamental questions of the origin and evolution of the Jovian atmosphere by allowing measurements of trace gases and removing interference (by overlapping ions) from key isotopes. Repeated sampling of the atmosphere at different altitudes will permit the determination of the altitude dependence of constituent abundances, thus enabling 
correlations with the locations of cloud layers and an identification of the source(s) of energy driving various chemical reactions.

The primary objective of the Probe mass spectrometer is thus to determine abundances and isotope ratios of 'major' (i.e., mole fraction $\geq 10^{-7}$ ) constituents as a function of altitude. The best precision is obviously achieved for the most abundant gases; it is estimated that the mixing ratio of $\mathrm{He}$ and $\mathrm{Ne}$ will be measured to an accuracy of $2 \%$ and molecules difficult to measure with mass spectrometers such as $\mathrm{H}_{2} \mathrm{O}, \mathrm{NH}_{3}$, and $\mathrm{H}_{2} \mathrm{~S}$ to a factor of two or better. To search for trace constituents at concentrations on the order of $1 \mathrm{ppbv}$, a sample enrichment system is added to the basic mass spectrometer, and for noble gases a purification cell is included. We discuss the expected results in the following sections.

The instrument was developed at the Goddard Space Flight Center in Greenbelt, Maryland, in collaboration with the University of Michigan Space Physics Research Laboratory in Ann Arbor, Mich., which developed the Electronics Subsystem, and the General Electric Company which developed and fabricated the hybrid electronics circuits. The Principal Investigator of the Galileo Probe Mass Spectrometer is H. B. Niemann of NASA-Goddard Space Flight Center, and the Co-Investigators are S. K. Atreya, G. R. Carignan, and T. M. Donahue of the University of Michigan, R. E. Hartle of NASA-Goddard Space Flight Center, D. M. Hunten of the University of Arizona, T. C. Owen of the University of Hawaii, and N. W. Spencer of the University of Maryland.

\subsection{SCIENCE GOALS AND GPMS CAPABILITIES}

As already mentioned in the Introduction, the mixing ratios of even the principal minor constituents in the Jovian atmosphere appear to be non-solar. This is consistent with the current paradigm for outer planet formation, which postulates the initial growth of a core by accretion of icy planetesimals to a mass of $10-15 M_{E}$, accompanied in its later stages with the gravitational attraction of surrounding nebular gases. Thus one anticipates atmospheres consisting of a mixture of two components: gases released from the planetesimals during accretion and/or through dissolution in the forming gaseous envelope, and the gases acquired directly from the solar nebula. This should lead to a general enrichment of all heavy elements except neon, which is not trapped in ices except at temperatures below $20 \mathrm{~K}$ (Bar-Nun et al., 1987). In fact, carbon, as manifested in methane, becomes progressively more enriched in the series Jupiter, Saturn, Uranus, Neptune, which is also a progression in the relative sizes of the planetary cores. This conforms to the predictions of the model. However, the elements arsenic (as $\mathrm{AsH}_{3}$ ) and phosphorus (as $\mathrm{PH}_{3}$ ) are more enriched on Saturn (compared to Jupiter) than are carbon and nitrogen (Noll et al., 1989, 1990). The dichotomy even exists in Jupiter itself (Table I). There must be some clues here about the differing internal structures of these two bodies, or differences in a way the elements were incorporated into the planets. To understand these differences, we need to know the abundances of more elements, in order to identify the source of the fractionation. For example, does it depend on the ability of a given element to form a gas that would be trapped or frozen into ices of an 
TABLE I

Gross atmospheric composition

A. Dominant isotope

\begin{tabular}{lll}
\hline Gas & Solar mixing ratio & Observations \\
\hline $\mathrm{H}_{2}$ & 0.84 & 0.90 \\
$\mathrm{He}$ & 0.16 & 0.10 \\
$\mathrm{H}_{2} \mathrm{O}$ & $1.7 \times 10^{-3}$ & $\sim 2 \times$ solar \\
$\mathrm{CH}_{4}$ & $7.2 \times 10^{-4}$ & $1.7 \times 10^{-3}$ \\
$\mathrm{Ne}$ & $2.5 \times 10^{-4}$ & \\
$\mathrm{NH}_{3}$ & $2.2 \times 10^{-4}$ & $<410^{-4}$ \\
$\mathrm{SiH}_{4}$ & $7.2 \times 10^{-5}$ & $<2.5 \times 10^{-9}$ \\
$\mathrm{H}_{2} \mathrm{~S}$ & $3.7 \times 10^{-5}$ & \\
${ }_{36} \mathrm{Ar}$ & $7.2 \times 10^{-6}$ & $7 \pm 1 \times 10^{-7}$ \\
$\mathrm{PH}$ & $7.5 \times 10^{-7}$ & \\
$\mathrm{HCl}$ & $3.8 \times 10^{-7}$ & \\
$\mathrm{HF}$ & $6.0 \times 10^{-8}$ & \\
\hline
\end{tabular}

B. Isotope ratios

\begin{tabular}{lll}
\hline Ratio & Solar mixing ratio & Observations \\
\hline $\mathrm{D} / \mathrm{H}$ & $3.4 \times 10^{-5}(?)$ & $2 \pm 1 \times 10^{-5}$ \\
${ }^{3} \mathrm{He} /{ }^{4} \mathrm{He}$ & $1.4 \times 10^{-4}(?)$ & \\
${ }^{18} \mathrm{O} /{ }^{16} \mathrm{O}$ & $2.0 \times 10^{-3}$ & $1.1+0.3 \times 10^{-2}$ \\
${ }^{13} \mathrm{C} /{ }^{12} \mathrm{C}$ & $1.1 \times 10^{-2}$ & \\
${ }^{15} \mathrm{~N} /{ }^{14} \mathrm{~N}$ & $3.6 \times 10^{-3}(?)$ & \\
${ }^{22} \mathrm{Ne} /{ }^{20} \mathrm{Ne}$ & $7.3 \times 10^{-2}(?)$ & \\
${ }^{34} \mathrm{~S} /{ }^{32} \mathrm{~S}$ & $4.4 \times 10^{-2}$ & \\
${ }^{38} \mathrm{Ar} /{ }^{36} \mathrm{Ar}$ & $1.9 \times 10^{-1}$ & \\
${ }^{21} \mathrm{Ne} /{ }^{20} \mathrm{Ne}$ & $2.4 \times 10^{-3}(?)$ & \\
${ }^{37} \mathrm{Cl} /{ }^{35} \mathrm{Cl}$ & $3.2 \times 10^{-1}$ & \\
${ }^{33} \mathrm{~S} /{ }^{32} \mathrm{~S}$ & $7.9 \times 10^{-3}$ & \\
\hline
\end{tabular}

accreting planetesimal? The abundances of the noble gases could prove to be very enlightening as a discriminant between internal and external processes. The apparent depletion of helium on Jupiter (Table I) is probably a mild example of the much more severe situation on Saturn, where helium is dissolving in the metallic hydrogen surrounding the core of the planet. The precise values of $\mathrm{He} / \mathrm{H}$ to come from the $\mathrm{HAD}$ experiment on Galileo (von Zahn and Hunten, 1992) will allow this interpretation to be sharpened, as will the GPMS determinations of other noble gas abundances.

In spite of these deviations from solar abundances, the absence of nuclear reactions on Jupiter and the vertical convection in its atmosphere suggest that primordial values of isotopic ratios will be preserved, provided that we measure them in dominant carriers. Thus we have an opportunity to determine the starting value for $\mathrm{D} / \mathrm{H}$ in the hydrogen gas in the solar nebula. The most recent estimate of this cosmologically important ratio from studies of ${ }^{3} \mathrm{He} /{ }^{4} \mathrm{He}$ in the solar wind and meteorites leads to 
$\mathrm{D} / \mathrm{H}=3.4 \pm 1 \times 10^{-5}$ (Anders and Grevesse, 1989). Measurements of $\mathrm{CH}_{3} \mathrm{D} / \mathrm{CH}_{4}$ in Jupiter's atmosphere yield $\mathrm{D} / \mathrm{H}=2 \pm 1 \times 10^{-5}$ (Gautier and Owen, 1989). Although the error bars overlap, there is a suggestion that these values may be higher than the local interstellar ratio $\left(\mathrm{D} / \mathrm{H}=1.5 \pm 1 \times 10^{-5}\right)$ and such a difference is recognized as a natural consequence of the nuclear burning of deuterium in stars, e.g., Geiss and Reeves (1981). A good determination of $\mathrm{D} / \mathrm{H}$ in the primordial solar nebula can thus be used (in principle!) to constrain models of Big-Bang nucleosynthesis and galactic evolution, particularly if abundances of other key elements can be determined in that same reservoir (Gautier and Owen, 1983). Jupiter offers us this opportunity, and the GPMS is designed to exploit it.

Yet another problem is posed by an observed secular increase of ${ }^{15} \mathrm{~N} /{ }^{14} \mathrm{~N}$ in lunar soils (Geiss and Bochsler, 1982; Kerridge, 1989). The two leading interpretations of this effect are an as yet undefined nuclear process in the convection zone of the Sun (Kerridge, 1989) and the existence of an as yet unidentified reservoir of 'light' nitrogen in condensed matter in the solar system (Geiss and Bochsler, 1982). Both camps agree that a precise determination of ${ }^{15} \mathrm{~N} /{ }^{14} \mathrm{~N}$ on Jupiter would provide an important constraint, since it will give the starting value for the nitrogen isotope ratio in the solar nebula. This value will also be important as an anchor for the interpretation of the ${ }^{15} \mathrm{~N} /{ }^{14} \mathrm{~N}$ enrichment found in the Martian atmosphere (Nier and McElroy, 1977).

Finally, there has been great interest in disequilibrium chemistry on Jupiter. What are the agents responsible for the pastel colors in Jupiter's clouds? Why is sulfur so deficient in the regions of the atmosphere that we can investigate by remote sensing? What is the relative importance of solar UV compared with lightning discharges in driving various chemical reactions? Do any of these reactions have any relevance to prebiotic chemistry on the primitive Earth? All of these questions have been discussed at length in the literature, but we have no good answers to any of them. We need more information, the kind we can only get by sampling the atmosphere directly, repeatedly, over a range of altitudes. This is just what the GPMS will do.

For the purposes of illustrating the capabilities of this instrument, we use a fictitious 'solar composition' atmosphere as a reference. The following tables thus reflect the solar ratios of elements (Anders and Grevesse, 1989) and the gases in which they are primarily incorporated in the Jovian atmosphere. Where available, these values are compared with actual observations. The reader is referred to Chapter 1 of Atreya (1986), Gautier and Owen (1989), Noll et al. $(1989,1990)$, and Carlson et al. (1991), for additional discussion.

\subsection{Direct InVESTigations}

The projected dynamic range of the Probe mass spectrometer is $10^{8}$, hence in principle, gases with mixing ratios greater than a few tens of ppbv can be detected. In practice, the precision of the measurement deteriorates rapidly as the limit of instrumental capabilities is approached. Nevertheless, the experiment can improve on some of the large uncertainties inherent in remote sensing for mixing ratios of most species above $5 \times 10^{-8}$. 
Inspection of Table I indicates that there are prospects of a rich harvest: at the very least eight elemental abundances and eight isotopic ratios; nine if sulfur is detected, as it probably will be. Silicon may not be found even at the deepest level reached by the Probe, but the search is an important one (see below). The over-solar abundances of heavy elements (except neon) predicted by the nucleation-accretion model for giant planet formation can be quantitatively evaluated and there is an opportunity to obtain several primordial isotope ratios. Important aspects of Jovian chemistry and cloud physics will be investigated by recording the abundances of $\mathrm{NH}_{3}, \mathrm{H}_{2} \mathrm{~S}$, and $\mathrm{H}_{2} \mathrm{O}$ at various altitudes. At the present time, the mixing ratios of these condensible gases and the locations of the clouds they are expected to produce (ammonia cirrus, ammonium hydrosulfide, ammonium hydroxide, water) are very poorly defined.

In particular, the abundance of water in the upper troposphere is so low that some authors have suggested it implies a global depletion of oxygen on Jupiter (Bjoraker et al., 1986). This conclusion is contradicted by models for the chemistry of the deep atmosphere that are constrained by observations of CO (Noll et al., 1988), requiring near solar abundances of water. Lunine and Hunten (1987) have suggested that moist vertical convection on Jupiter is limited to narrow plumes, resulting in the very low relative humidity observed in the upper atmosphere. The global abundance has been re-assessed by Carlson et al. (1991), in the most comprehensive model of the Voyager IRIS observations presented to date. These authors find the $\mathrm{H}_{2} \mathrm{O}$ abundance on Jupiter to be at least 1.5 times the solar value with a factor of two enrichment providing the best fit to the observations. The Carlson et al. model has an $\mathrm{NH}_{4} \mathrm{SH}$ cloud layer at 1.9 bar and the $\mathrm{H}_{2} \mathrm{O}$ cloud base is at $2.3 \mathrm{bar}$. This location for the ammonium hydrosulfide cloud agrees well with the model developed by Larson et al. (1984) and Atreya and Romain (1985) to explain their low upper limit on $\mathrm{H}_{2} \mathrm{~S}$ (Table I). We have adopted the Carlson et al. best-fit value for the $\mathrm{H}_{2} \mathrm{O}$ mixing ratio in Table $\mathrm{I}$, although it is strongly model dependent. The measurements with the GPMS down to at least 10 bar will reveal the sulfur and oxygen mixing ratios by direct measurement for the first time. With careful interpretation, it may be possible to explore the role played by sulfur (if it has one!) in generating observable chromophores in the Jovian clouds.

\subsection{THE USE OF ENRICHMENT CELLS}

\subsubsection{Noble Gases}

Removal of hydrogen and other chemically-active species by the noble gas cell gives the following mixing ratios for the noble gases:

TABLE II

Noble gas abundances

\begin{tabular}{ll}
\hline $\mathrm{He}$ & 1.0 \\
$\mathrm{Ne}$ & $1.3 \times 10^{-3}$ \\
$\mathrm{Ar}$ & $3.7 \times 10^{-5}$ \\
$\mathrm{Kr}$ & $1.7 \times 10^{-8}$ \\
$\mathrm{Xe}$ & $1.7 \times 10^{-9}$ \\
\hline
\end{tabular}


With a dynamic range of $10^{8}$, it may just be possible to reach krypton and xenon. This will depend on the abundances in Jupiter's atmosphere. It should be recognized that cosmic abundances of these important constituents are poorly determined, since they have never all been measured in a single, undisturbed reservoir. Jupiter offers the first opportunity to do this, although the analysis will have to include possible solubility effects in the interior of Jupiter and the differences in the ways these gases can be incorporated in the ices of planetesimals (Lunine and Stevenson, 1985; Bar-Nun et al., 1987). The scaling to hydrogen will come from the unpurified sample where mixing ratios of $\mathrm{He}, \mathrm{Ne}$, and $\mathrm{Ar}$ to $\mathrm{H}_{2}$ will be measured directly.

Removal of hydrogen increases the relative abundances of all species by approximately a factor of 10 . Thus the isotopic ratios of the constituents discussed in the previous section can be measured with greater precision in this mode. Removal of hydrogen will greatly diminish interference with the ${ }^{3} \mathrm{He} /{ }^{4} \mathrm{He}$ determination, which is of fundamental importance in comparing the deduction of $\mathrm{D} / \mathrm{H}$ in the primordial solar nebula from meteoritic helium measurements with the direct measurement that will be made by the GPMS.

\subsection{OTHER POSSIBILITIES}

\subsubsection{Photochemistry, Lightning, and Internal Heat}

For future reference, the expected abundances of a number of other classes of compounds are listed in Tables III-V, even though it cannot be asserted that they are

TABLE III

Photochemically produced species

\begin{tabular}{llc}
\hline Gas & & 'Maximum' mixing ratio \\
\hline $\mathrm{C}_{2} \mathrm{H}_{2}$ & (observed) & $3 \times 10^{-6}$ \\
$\mathrm{C}_{2} \mathrm{H}_{6}$ & (observed) & $3 \times 10^{-5}$ \\
$\mathrm{C}_{2} \mathrm{H}_{4}$ & (observed) & $7 \pm 3 \times 10^{-9}$ in north polar region \\
$\mathrm{C}_{3} \mathrm{H}_{8}$ & (observed) & $<6 \times 10^{-7}$ in north polar region \\
$\mathrm{C}_{3} \mathrm{H}_{4}$ & (observed) & $2.5_{-1}^{+2} \times 10^{-9}$ in north polar region \\
& & $<7 \times 10^{-10}$ at mid latitudes \\
$\mathrm{C}_{4} \mathrm{H}_{2}$ & (observed) & $<3 \times 10^{-10}$ \\
$\mathrm{C}_{6} \mathrm{H}_{6}$ & (observed) & $2+1 \times 10^{-9}$ in north polar region \\
& & $<2 \times 10^{-10}$ at mid latitudes \\
$\mathrm{HCN}$ & & $2 \times 10^{-9}$ \\
$\mathrm{~N}_{2}$ & (predicted) & $2 \times 10^{-9}-10^{-6}$ \\
$\mathrm{~N}_{2} \mathrm{H}_{4}$ & (predicted) & $3 \times 10^{-10}$ \\
$\mathrm{CH}_{3} \mathrm{NH}_{2}$ & (predicted) & $\sim 10^{-9}$ \\
$\mathrm{P}_{2}, \mathrm{P}_{4}$ & (predicted) & $?$ \\
\hline
\end{tabular}

detectable. With a potential enrichment for some of these species by a factor 100 to 500 , several of them may in fact be brought into the measurable range. Abundance determinations will then depend on measurements relative to species that can be detected directly (without enrichment) as calibrated by the laboratory model of the instrument. 
TABLE IV

Chemically active trace constituents

\begin{tabular}{lll}
\hline Gas & Mixing ratio & Observations \\
\hline $\mathrm{CO}$ & $1 \times 10^{-9}$ & $1.3 \pm 0.3 \times 10^{-9}$ \\
$\mathrm{GeH}$ & $8.5 \times 10^{-9}$ & $0.7 \pm 0.2 \times 10^{-9}$ \\
$\mathrm{H}_{2} \mathrm{Se}$ & $4.5 \times 10^{-9}$ & \\
$\mathrm{HBr}$ & $8.5 \times 10^{-10}$ & \\
$\mathrm{~B}_{2} \mathrm{H}_{6}$ & $7.5 \times 10^{-10}$ & \\
$\mathrm{AsH}_{3}$ & $4.7 \times 10^{-10}$ & $2.2 \pm 1.1 \times 10^{-10}$ \\
$\mathrm{H}_{2} \mathrm{Te}$ & $3.4 \times 10^{-10}$ & \\
$\mathrm{SnH}_{4}$ & $2.7 \times 10^{-10}$ & \\
$\mathrm{HI}$ & $6.7 \times 10^{-11}$ & \\
$\mathrm{SbH}_{3}$ & $2.2 \times 10^{-11}$ & \\
\hline
\end{tabular}

TABLE V

Species from electric discharges.

Concentrations unknown

$\mathrm{CH}_{3} \mathrm{~S}$

$\left(\mathrm{C}_{2} \mathrm{H}_{5} \mathrm{~S}\right)_{2}$

$\mathrm{CH}_{3} \mathrm{CN}$

$\mathrm{HCN}$

The abundances of the gases produced photochemically in the planet's upper atmosphere that will be measured by the GPMS are difficult to evaluate from present information for two reasons: (a) both the analysis of observations and theoretical calculations are strongly dependent on model atmospheres and (b) the amounts of these gases actually sampled by the Probe mass spectrometer will be a strong function of altitude. The figures given are attempts to define maximum values; the actual amounts may be lower.

The discovery of lightning on Jupiter by the Voyager spacecraft has emphasized the possibility of the production of non-equilibrium species in the Jovian troposphere. This means that one should search for examples of the compounds that have been produced in laboratory experiments simulating an electric discharge in a Jovian mixture of gases. Of particular interest are $\mathrm{HCN}, \mathrm{C}_{2} \mathrm{H}_{2}, \mathrm{CH}_{3} \mathrm{CN}$ and a variety of organic compounds including some containing sulfur.

At the base of the proposed Probe trajectory, at a pressure of $15-20$ bar, there is a possibility that trace compounds will be sampled that are only at equilibrium at much lower, hotter levels of the atmosphere. Traces of these constituents might survive to the deepest level where sampling is possible in much the same way $\mathrm{CO}, \mathrm{GeH}_{4}, \mathrm{PH}_{3}$, and $\mathrm{AsH}_{3}$ are brought to still higher levels of the atmosphere where they have been observed spectroscopically. An obvious and important candidate in this category is silane- $\mathrm{SiH}_{4}$ whose enriched solar abundance mixing ratio of $\sim 10^{-4}$ should only be reached at temperatures above $1200 \mathrm{~K}$. 


\section{Instrument Description}

\subsection{INTRODUCTION}

Within the constraints of volume, power, and bit rate, a number of compromises must be made in the design of an atmospheric composition experiment. An important advantage of a mass spectrometer is its impartiality: within its mass and sensitivity range it detects everything admitted to it, and it is therefore ideal for an exploratory mission like the Galileo Probe. The instrument chosen is a quadrupole mass spectrometer supplemented by rather complex 'plumbing' with sample inlets and gas-handling, pressure-reducing, and pumping systems. To enhance the range of measurements the basic sample inlet is supplemented by three selective subsystems: a noble-gas purifcation cell and two sample enrichment cells for the more complex compounds. Advantage is taken of non-evaporable chemical getter technology for pumping hydrogen and the reactive minor constituents and thus avoid the increased complexity and reliability risk associated with moving parts in mechanical pumps such as turbomolecular pumps.

The approach to the electronics support system is also straightforward and conventional. Extensive use was made of hybrid circuit packaging because of weight and size limitation. The complexity of microprocessor control is not desirable given the devastating radiation environment that must be traversed before entry into the atmosphere of Jupiter. It is also not necessary since all control functions can be handled with conventional electronics and the measurement sequence followed during descent is stored reliably in read only memory. A summary of the instrument specification is given in Table 6.

\subsection{SAMPLE INLET AND ENRICHMENT SYSTEMS}

The inlet system shown schematically in Figure 1 consists of two fully self-contained units which operate in time sequence as the Probe descends through the atmosphere. Both units contain an ambient atmosphere flow system whose gas inlets are placed near the apex of the Probe, and whose exit ports are placed at the minimum pressure point inside the Probe. Ambient atmospheric pressure at the exit is assumed as a worst case condition. The pressure difference (approximately 6 mbar) between the stagnation point and the ambient pressure point causes a flow past the pressure reducing leaks. Inlet and outlet ports are sealed by metal-ceramic devices and kept under vacuum prior to entry. They will be opened in sequence after entry by redundant pyrotechnic actuators.

A small fraction of the gas flowing through the high pressure flow system from Inlet 1 to Outlet 1 or Inlet 2 to Outlet 2 is conducted through the pressure reducing leaks L1 or $\mathrm{L} 2$ into the ionization region of the ion source. The leaks, which are arrays of glass capillaries (typically seven capillaries per leak) with inside diameters ranging from $1.5 \mu \mathrm{m}$ to $6 \mu \mathrm{m}$ have conductances chosen so that the pressure in the ion source does not exceed $10^{-4}$ mbar. The capillaries were fabricated in a proprietary process by the Galileo Electro Optics Corp. of Sturbridge, Massachusetts. The materials used for the inlet system plumbing are primarily nickel and inconel. The surfaces in contact with the sampled gases were passivated by a silinizing process. 
TABLE VI

Instrument parameter summary

\begin{tabular}{|c|c|}
\hline Parameter & Characteristic \\
\hline \multirow[t]{3}{*}{ Inlet system } & 2 glass capillary array direct leaks \\
\hline & 1 scrubber (noble gas analysis) \\
\hline & 2 enrichment cells \\
\hline Ambient pressure range & 0.15 to 20 bar nominal \\
\hline \multirow[t]{4}{*}{ Mass analyzer } & Quadrupole; field radius $5.0 \mathrm{~mm}$ \\
\hline & field length $150 \mathrm{~mm}$ \\
\hline & Operating frequency; $2.83 \mathrm{MHz}, 2$ to $19 \mathrm{amu}$ \\
\hline & $1.13 \mathrm{MHz}, 20$ to $150 \mathrm{amu}$ \\
\hline Ion source & $\begin{array}{l}\text { Electron impact/dual filament/variable energy } \\
(75 \mathrm{eV}, 25 \mathrm{eV}, 15 \mathrm{eV})\end{array}$ \\
\hline Ion detector & Secondary electron multiplier/pulse counter \\
\hline Mass range & 2 to $150 \mathrm{amu}$ \\
\hline Scan format & $\begin{array}{l}\text { Stepping, Integer or } 0.125 \mathrm{amu}, 0.5 \mathrm{~s} \text { per mass step. } \\
\text { Nominal } 75 \mathrm{~s} \text {, scan period }(2 \text { to } 150 \mathrm{amu})\end{array}$ \\
\hline Dynamic range & $10^{8}$ \\
\hline Mass analyzer resolution & $\begin{array}{l}\text { Unit mass, flat top peaks, nominal } 10^{-8} \text { crosstalk for } \\
\text { adjacent masses from } 2 \text { to } 60 \mathrm{AMU} \text {; larger crosstalk } \\
\text { for higher masses and for ions with non-thermal } \\
\text { energies }\end{array}$ \\
\hline Pressure range & $10^{-13}$ to $10^{-4}$ mbar (ion source) \\
\hline Data rate & 32 bps \\
\hline \multirow{2}{*}{ Electronics } & Read Only Memory (ROM) \\
\hline & $\begin{array}{l}\text { Controlled descent sequence } 8192 \text { program steps } \\
\text { ( } 16 \text { bits/step). Ground command override capability } \\
\text { during checkout and cruise }\end{array}$ \\
\hline Temperature range & $-20^{\circ} \mathrm{C}$ to $50^{\circ} \mathrm{C}$ operating \\
\hline Viewing requirements & $\begin{array}{l}\text { Sample inlet port near stagnation point; } \\
\text { Sample outlet port near minimum pressure point }\end{array}$ \\
\hline Deployment mechanism & $\begin{array}{l}\text { (1) Metal ceramic breakoff caps, pyrotechnically } \\
\text { actuated } \\
\text { (2) Valves, solenoid operated }\end{array}$ \\
\hline Pumps & Non-evaporable getters and sputter ion pump \\
\hline Power & $\begin{array}{l}\text { (1) Instrument: } 13 \mathrm{~W} \text { avg } \\
\text { (2) Pumps and heaters: } 12 \mathrm{~W}\end{array}$ \\
\hline Total energy for $60 \mathrm{~min}$ descent time & $120 \mathrm{~kJ}$ \\
\hline Weight & $13.2 \mathrm{~kg}(29.11 \mathrm{lbs})$ \\
\hline
\end{tabular}

The sample enrichment systems are an integral part of the ambient atmosphere flow systems. Atmospheric gas, after passing by the capillary leaks L1 or L2, will be conducted via valve V1 or V6 to the enrichment cells which contain getters $\mathrm{G} 1$ through $\mathrm{G} 4$ that, when activated, chemically bind reactive gases during the measurement sequence and thus allow a pure noble gas analysis. The enrichment cells $\mathrm{C} 1$ and $\mathrm{C} 2$ are packed with adsorbing compounds chosen to adsorb complex hydrocarbons. The material found through testing to be most suitable for this experiment is CARBOSIEVE, 80-100 mesh, a porous carbon structure of fixed pore size used commercially as a stationary phase in packed gas chromatographic columns (available from Supelco, Inc. 


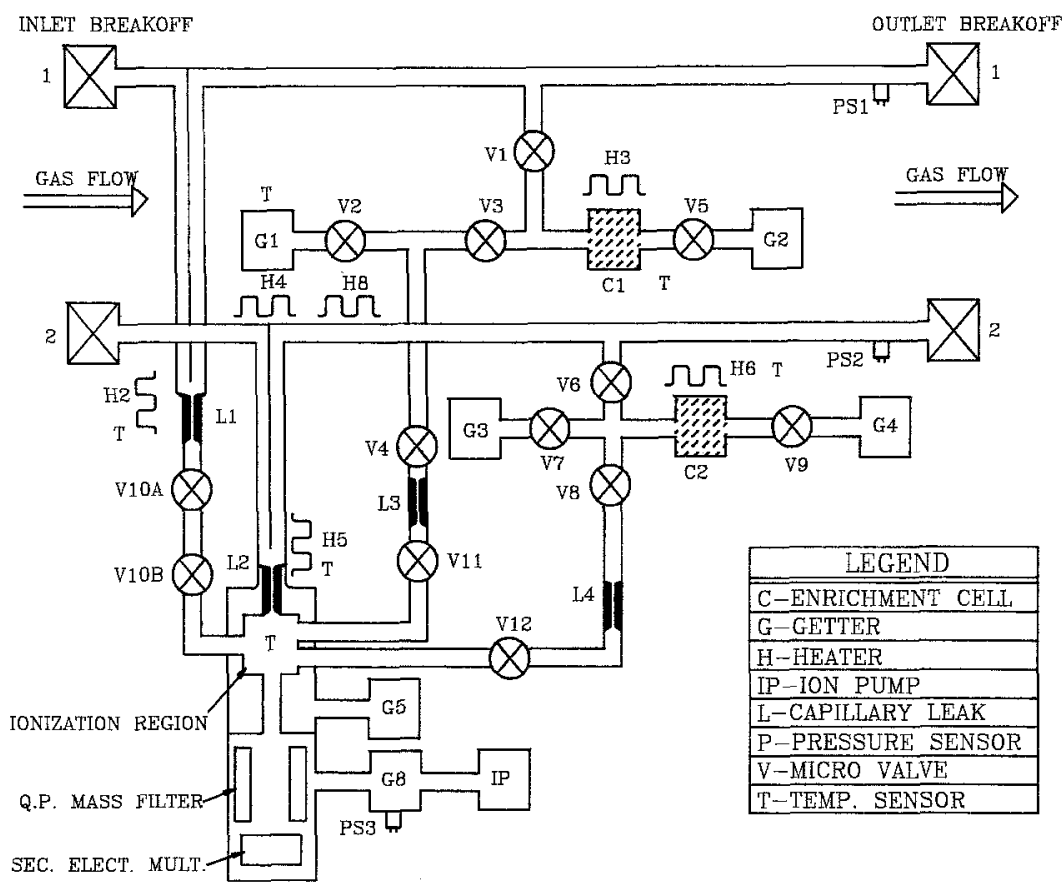

Fig. 1. Schematic of the gas inlet system and connection to the mass spectrometer sensor. Two parallel gas inlet/outlet systems are employed to provide gas samples to the direct leaks, L1 and L2, and to the two sample enrichment systems centered around $\mathrm{C} 1$ and $\mathrm{C} 2$.

in Bellefonte, PA). Gases adsorbed by the enrichment cells will be released by a programmed heating cycle during the Probe descent. During these cycles the cells are isolated from the flow system and the getters by valves V1 through V9. The valves are solenoid operated microvalves manufactured by Aker Industries (formerly Energy Research \& Generation, Inc.) of Oakland, California. At specified times the gas trapped in the cells is conducted through separate capillary leaks L3 and L4 to the ionization region. The enrichment factor depends on the chemical and physical properties of the sample gas. In general it increases with the molecular weight of the species. This is qualitatively illustrated in Figure 2 where mass spectra obtained with analog laboratory recorders are shown for noble gases and hydrocarbon gas mixtures before and after enrichment. The substantial xenon enrichment further improves the concentration measurement of xenon since the expected mixing ratio is marginally measurable by direct analysis.

After use the sample enrichment leaks L3 and L4 and the first direct leak L1 will be isolated from the ion source by solenoid operated valves V10, V11, and V12 to prevent the ion source pressure from exceeding its optimum value, and also to permit repeated observation of system background pressure after the initial sampling and enrichment sequences are completed. The second independent inlet system will be opened to the atmosphere after the first system has been isolated from the ion source. Sample 

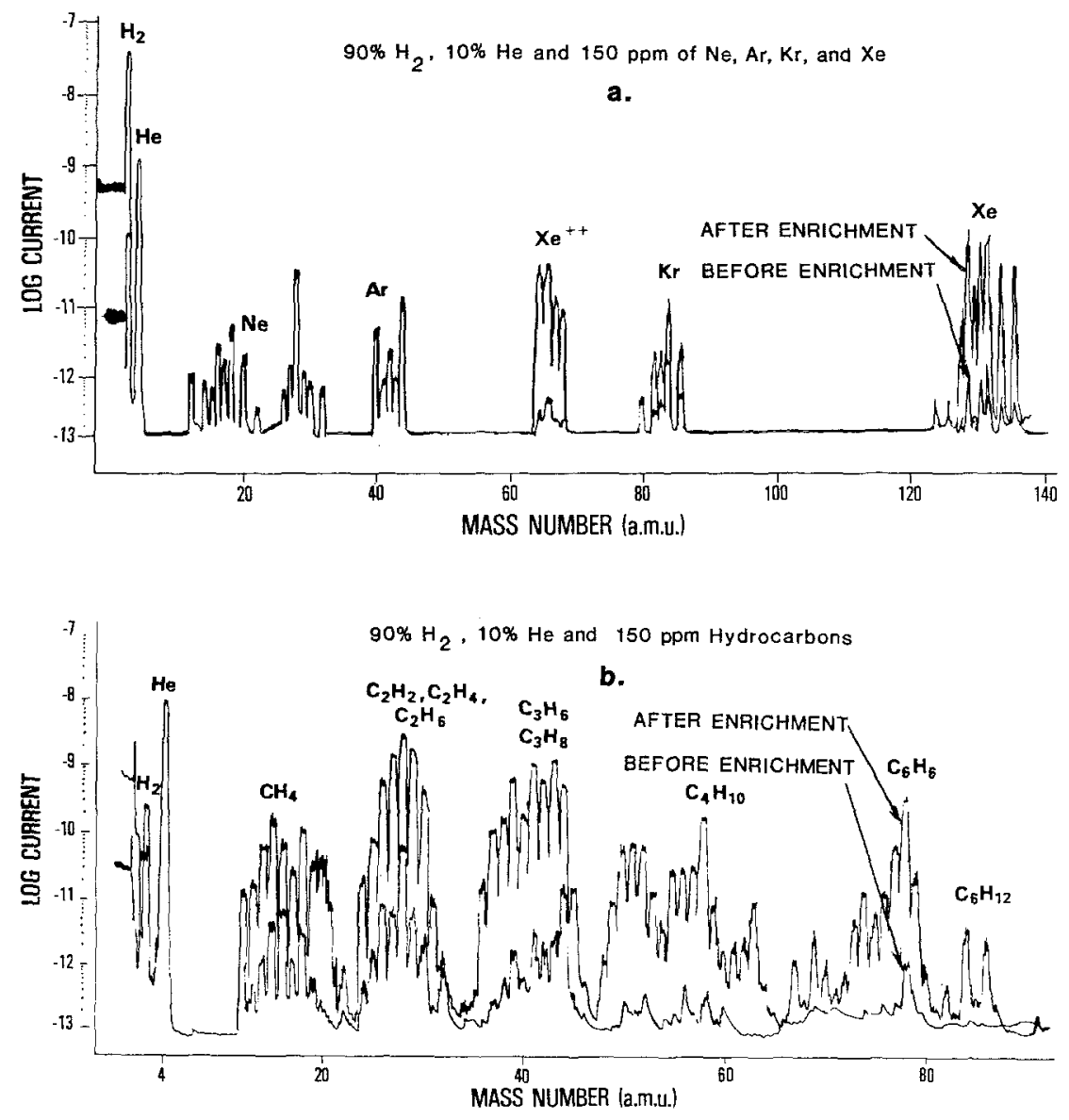

Fig. 2. Mass spectra showing enrichment obtained when gas processing is used to remove the major constituent $\mathrm{H}_{2}$ from a $90 \% \mathrm{H}_{2}$ and $10 \% \mathrm{He}$ mixture containing constituents each of 150 ppmv. (a) Rare gas enrichment. Note the substantial enrichment of Xe obtained. Expected Xe ratios are marginably measurable by direct analysis. (b) Hydrocarbon enrichment. There is a substantial enrichment of the $\mathrm{C}_{3}-\mathrm{C}_{4}$ hydrocarbons with a somewhat less enrichment for methane. For illustration the spectra were recorded analog with laboratory recording equipment.

distortion caused by gas-surface interactions is minimized by directing the high pressure flow against the capillary leak and by locating the leaks in the ion source so that the gas leaves the capillaries on the ion source side directly through the ionizing electron beam. The gas emitted from the capillaries can thus be ionized and analyzed without having experienced previous surface collisions with the ion source walls. Limits of the pumping speeds imposed by weight and power constraints in a flight system do not permit instant removal of the gases from the ion source after they initially pass the ionization region. A component of randomized gas therefore contributes to the measurement. The ratio of the direct beaming to the randomized component strongly depends on the system geometry. A ratio of approximately $5: 1$ was achieved with the ion source 
design of the flight instrument. It is most critically affected by the distance between the electron beam and the capillary exit and the cross section of the electron beam.

A cross-sectional view of the actual ion source is shown in Figure 3. The gas flow path for the second inlet system near leak L2 is marked by arrows. The gas flow path was

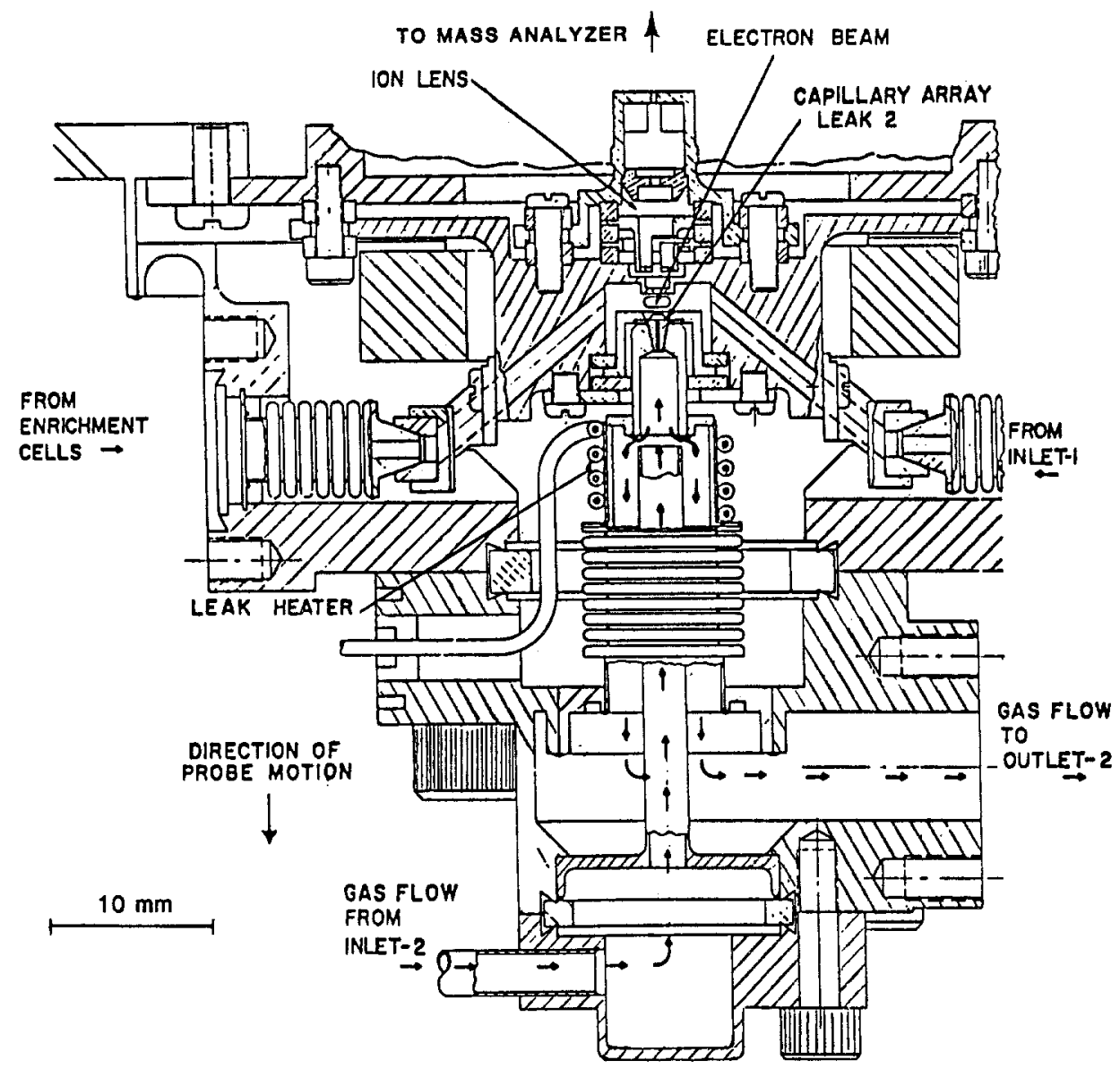

Fig. 3. Cross section of the Galileo Probe Mass Spectrometer ion source showing direct beaming capillary leak and the various gas flow connections.

designed to minimize clogging of the capillary leak array by condensible gases, e.g., water droplets should they exist. It is believed that the cloud particles on Jupiter are condensates in vapor pressure equilibrium with their surroundings. They are unlikely to clog any part of the inlet system, which is considerably warmer than the ambient atmosphere and will quickly evaporate them. Large droplets, should they overcome the gravitational potential while moving through the inlet lines, will be trapped in the cup, shown for example at the bottom of Figure 3. Involatile smog particles, such as the concentrated sulfuric acid on Venus are unlikely to be encountered. A droplet trap arrangement for inlet 1 is similar to that shown for inlet 2. Also shown in Figure 3 are 
the connecting vacuum flanges through which the sample gases coming from the first leak and the leaks that supply the enriched and purified samples enter the ion source.

The measurement sequence, illustrated in Figure 4(b), shows the time dependence of the total ion source pressure during the Probe descent. For reference the ambient pressure and temperature are shown in Figure 4(a) as a function of time. During the cruise phase of the mission all microvalves are open. Following the sequence start event,

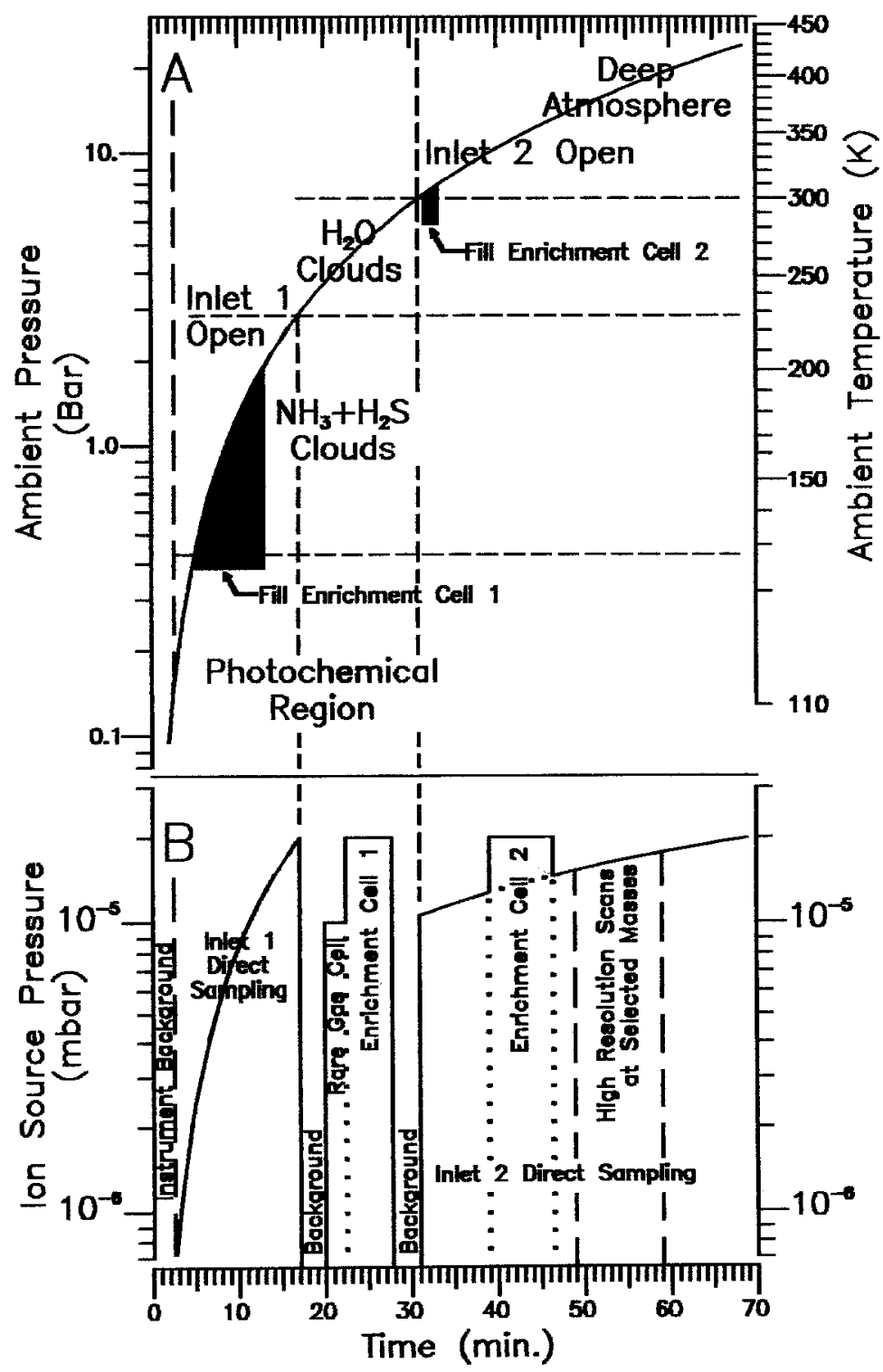

Fig. 4. (A) Ambient Pressure-Time Profile. (B) Typical Measurement Sequence; Ion Source Pressure-Time Profile. 
microvalves V1, V3, V4, V6, V7, and V8 are closed which is the initial condition for sampling. The first inlet breakoff is opened when the Probe reaches a pressure level of approximately $150 \mathrm{mb}$. Approximately one second later the first outlet breakoff is opened, causing the ambient atmosphere to flow past the capillary leak L1 through which a small fraction of the atmosphere is conducted into the ion source. While the direct analysis is made, valve $\mathrm{Vl}$ is opened for $8 \mathrm{~min}$ to allow ambient gas to flow through enrichment cell $\mathrm{C} 1$ until getter $\mathrm{G} 2$ is saturated with hydrogen and the getter housing volume is filled with gas. Next valves V1 and V5 are closed, valves V2 and V3 are opened and the remaining reactive gas, mostly hydrogen, is absorbed by getter G1. Remaining in the enclosed volume are the noble gases and some residual hydrogen whose partial pressure is reduced by approximately five orders of magnitude determined by the equilibrium vapor pressure of the hydrogen dissolved in getter G1. In the third step valves V2 and V3 are closed and valve V4 is opened introducing a fraction of the gas into the volume enclosed by valves V2, V3, and V4 through leak L3 into the ion source. Prior to opening valve V4, valves V10A and V10B are closed and the ion source and analyzer section of the mass spectrometer are evacuated to background via getters G5 and G8 and the sputter ion pump IP. Mass spectra are obtained during the pump down time to record the remaining background gases. The noble gases subsequently introduced into the ion source through leak L3 are analyzed for $2.5 \mathrm{~min}$. During this time enrichment cell $\mathrm{C} 1$ is heated for $5 \mathrm{~min}$ to $200^{\circ} \mathrm{C}$, the gases are desorbed, and, after opening valve V3, they are added to the noble gases flowing through $\mathrm{L} 3$ into the ion source. After $5.0 \mathrm{~min}$ of analysis of these gases during which the cell temperature is maintained at $200^{\circ} \mathrm{C}$, valve V11 is closed and the mass spectrometer is pumped once more to background pressure levels while the partial pressure of the background gases are measured. Inlet system 1 is now completely and irreversibly isolated from the mass spectrometer and the sequence described is repeated with inlet system 2 for which a separate noble gas measurement cycle is not provided. Leak $\mathrm{L} 2$ cannot be isolated from the ion source in order to allow direct gas beaming into the ionization region. Hence, the contents of enrichment cell $\mathrm{C} 2$ will be superimposed on the direct measurement as illustrated in Figure 4(b).

\subsection{ION SOURCE}

The importance of minimizing gas-surface interactions in the high vacuum side requires that the ion source be very compact and an integral part of the sample inlet system. Electron impact ionization is used in a miniature, dual filament ion source. The second filament provides redundancy and is turned on automatically should the first filament break or burn out. A collimated electron beam is directed through the ionization region past the capillary leak L2 shown schematically in Figure 1 and the physical location in Figure 3. The electron beam energy is varied to permit species identification and discrimination by observing spectra of fragmentation patterns at several different electron energies. The other leaks L1, L3, and L4 are connected to the ionization region via short tubes as indicated schematically in Figure 1. Chemical reactions of gases on the surfaces of the hot filament are minimized by isolation through narrow slits and by 
separate pumping of the filament region. Ions are focused into the mass analyzer for filtering by a three-element ion lens.

\subsection{QUADRUPOLE MASS ANALYZER}

The quadrupole mass filter was first described by Paul and Steinwedel (1953), and Paul et al. (1958). The reader is also referred to the book by Dawson (1976) for detailed discussions of quadrupole mass spectrometers and applications.

The quadrupole analyzer filters the ion beam produced by the ion source, transmitting ions of a chosen charge to mass ratio only. The transmitted ions are focused on a secondary electron multiplier detector. The radius of the quadrupole field is $5 \mathrm{~mm}$ and the field length is $150 \mathrm{~mm}$. Mass selection is achieved by application of radio frequency and static potentials of varying magnitude to diagonal rod pairs. The selected mass value is determined by the relation $m=0.55 \mathrm{~V} / \mathrm{f}^{2}$ (amu) where $V$ is the amplitude of the applied radio-frequency voltage in $\mathrm{V}$ and $f$ is the frequency in $\mathrm{MHz}$. To allow voltage scanning over a sufficient amplitude range two separate radio frequencies were used, $2.83 \mathrm{MHz}$ for 2 to $19 \mathrm{amu}$ and $1.13 \mathrm{MHz}$ for 20 to $150 \mathrm{amu}$. The quadrupole mass filter has been chosen in preference to a magnetic sector spectrometer because of its light weight, versatility, high resolution, and simplicity. The only dimensionally critical element in the system is the precision rod assembly whose rigid and compact design has been proven by application in previous flight experiments and vibration and temperature testing to be extremely stable.

\subsection{Pumping system}

The pumping system establishes a flow of sample gas though the ion source at a particular pressure when a sampling device is opened, and, after analysis and closure, removes the sample from the ion source region. Non-evaporable getters and a sputter ion pump are used because of their simple adaptation to space flight systems. They depend only on electrical power for operation, without moving parts. Their application to the Galileo Probe Mass Spectrometer requires care because hydrogen and helium are the major gases in the atmosphere. While hydrogen is absorbed at a very high rate by getter materials, helium absorption is practically zero. Sputter ion pumps also pump hydrogen with high efficiency but hydrocarbons are synthesized in the pump by reactions of hydrogen ions with carbon trapped in the pump surfaces. The effective pumping speed for helium is usually small because of the low ionization cross section of helium and the requirement that helium be buried physically in the pump elements since it does not become chemically bound or go into solution like hydrogen. This requires sputtering of comparatively large amounts of cathode material which tends to release larger quantities of gases previously entrapped in the pump surfaces. Thus, to eliminate the synthesis of hydrocarbons in the sputter pump a cascaded pump system is used. A high capacity baffled getter pump is operated in cascade with a sputter ion pump. The gas flow from the mass spectrometer into the getter pump is conductance limited to maintain a constant pumping speed during the measurement phase. Hydrogen and all other reactive gases are adsorbed by the getter before they reach the sputter 
pump. Gases emitted by the pump pass the getter first before they can enter the mass spectrometer and their contribution to the ion source gas is therefore significantly reduced. Small sputter pump instabilities, not fully avoidable with the present state of technology, are buffered by the preceding getter chamber. The getter material used is sintered zirconium graphite available from SAES Getter of Milan, Italy as type ST171. It is fabricated in a proprietary process. After activation at approximately $900^{\circ} \mathrm{C}$ for 45 min while the instrument is connected to the laboratory vacuum pumping system, the getters remain active at room temperature until they become saturated at the end of the Probe descent. Getters G5 and G8 are dimensioned approximately five times larger than required for the gas load expected during the descent in order to maintain constant pumping speed. The cathode materials of the sputter ion pump are tantalum and titanium and the electrode geometry is optimized to enhance pumping of helium by ion implantation and burial. Pumping speed is conductance limited at the pump flange to $21 \mathrm{~s}^{-1}$. The magnetic field of the sputter ion pump is 0.2 Tesla over an effective area of $35 \mathrm{~cm}^{2}$. The yoke is designed to minimize the stray field. Magnetic shielding was also provided to the ion source housing to cancel the stray field of the pump because of its location directly above the ion source. The sample inlet system and vacuum pump assembly are shown in Figure 5.

\subsection{ELECTRONIC SYSTEM}

In adapting previous concepts for the electronics to the Galileo requirements, simplicity has been a major consideration. Power commands and timing events are accepted and processed by the logic system. The data of the primary measurement are stored in an output register for interrogation by the spacecraft telemetry system. A block diagram of the electronic system is shown in Figure 6.

The instrument is under control of the programmer which is an array of Read-OnlyMemory (ROM) devices which produces an 8192-word, 16-bit look-up table and an output register to hold the 16-bit word in current usage. Each one half second the ROM is incremented and the instrument is configured for the next measurement. Thus during each of 8192 one half second intervals each of six instrument variables, e.g., mass number, ionization energy, inlet system configuration, etc., can be configured to any allowable state. The application of power causes the instrument to begin executing a programmed 256 step 'test' sequence. The instrument remains locked in this 'test' mode until the SEQUENCE START command is received from the Probe.

As mentioned above mass number selection in a quadrupole is a function of amplitude and frequency of the RF signal applied to the rods. Two frequencies are being used to cover the mass range of 2 to 150 amu (Table VI). In each frequency range mass number is proportional to the RF amplitude. The actual mass scanning range is slightly larger than the nominal values quoted above for occasional high-resolution peak scanning past the center of the mass peaks to verify tuning and mass resolution. The mass peak width is kept approximately constant over the mass range 2 to 150 amu by proper choice of the dc and RF voltages.

The ion source requires an electrode supply of well-regulated voltages and a feedback 


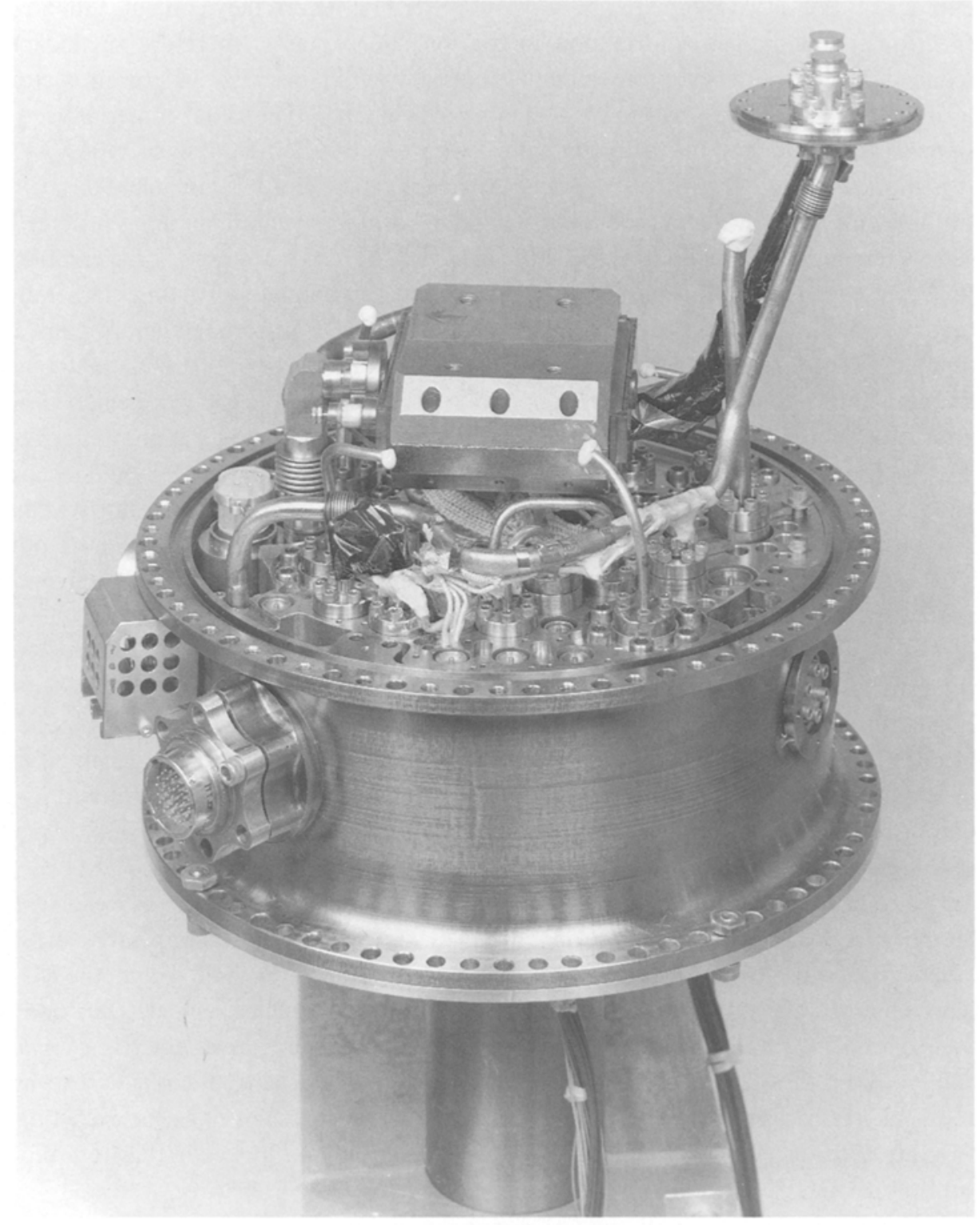

Fig. 5. Gas sample inlet system for the Galileo Probe Mass Spectrometer.

controlled emission regulator for the ionizing electron beam gun. For the Galileo application three different ionization energies are programmer selected by changing appropriate ion source potentials. The ion source, as previously noted, is provided with two redundant filaments which are powered by redundant emission regulators. This implementation simplifies the design and, of course, increases reliability.

A high voltage supply of nominal $3 \mathrm{kV}$ operates the secondary electron multiplier ion 


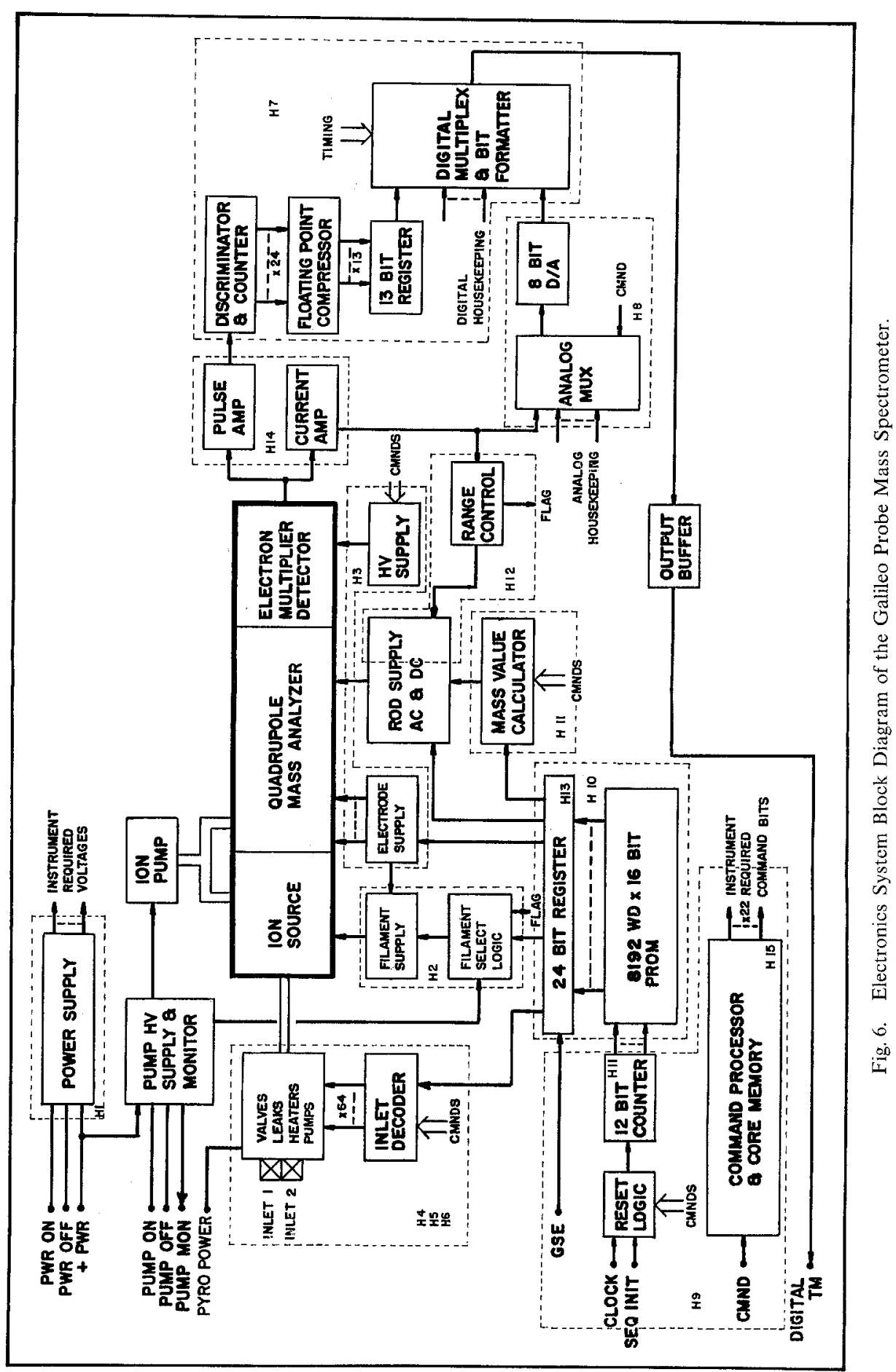


detector. Command capability to optimize the secondary electron multiplier gain through the selection of one of four values is provided. The ion arrival rate at the detector during each one half second during the descent constitutes the primary measurement. Pulse counting will range from a rate of about $5 \times 10^{7} \mathrm{cts} \mathrm{s}^{-1}$ down to rates as low as one count per half second integration. At ion arrival rates exceeding the upper count limit the instrument will be desensitized automatically. A logarithmic (base 2) compressor is used with a 9-bit mantissa and 4-bit exponent. This provides a full scale of $3 \times 10^{7}$ per range and a resolution of one part in 512 .

The electronics system was constructed using multi-layer printed circuit board technology. Weight and size constraints for the Galileo Probe instruments required that approximately $90 \%$ of the electronics components were packaged in multi-layer hybrid form. To meet structural requirements the circuit boards were mounted on a cross web structure enclosing the quadrupole analyzer and ion detector section. A photograph of the electronics assembly is shown in Figure 7. The average power consumption of the electronics system is $13 \mathrm{~W}$. Additional pump and heater power of $12 \mathrm{~W}$ maximum is required during the descent.

Since the Probe is not pressurized the instrument is enclosed by a pressurized envelope made of titanium to save weight. Pressurization $\left(1.2\right.$ bar $\mathrm{N}_{2}$ ) prevents corona and condensation during the descent, and defers collapse. The weight of the instrument is $13.2 \mathrm{~kg}$ (29.11 lbs.). The fully asembled instrument is shown in Figure 8. Also shown in the figure are the inlet and outlet breakoff devices of the sample inlet system.

\subsection{RELIABILITY AND REDUNDANCY}

Much consideration is always given to reliability in the design of scientific space flight instruments. Of particular concern for the Galileo mission is the requirement for long instrument life which has increased from the original 3 years to more than 10 years. This increase was due to various programmatic changes in the mission and schedule delays caused by the tragic Challenger accident. Although there are no special long-life verification test results available for the instrument, an examination of the materials and components used in the instrument let us conclude that we expect reliable operation of the instrument over the required time period.

Of particular concern is the vacuum integrity of the mass spectrometer system. To maintain a sufficiently clean ion source environment for trace gas detection, it is necessary to keep the sample inlets and the analyzer section under high vacuum and sealed until the measurement sequence begins. Getter and sputter ion pump loading due to small vacuum leaks from the pressurized housing or from surface outgassing can seriously degrade or even destroy the capacity of the instrument to perform during entry. However, leak and outgassing tests performed after pinch off from the vacuum stand and vibration tests indicated leak rates low enough to exceed the required lifetime by more than a factor of three. Post launch and first earth encounter check out of the instrument also verified that the vacuum integrity was maintained during and after the launch and after vehicle separation maneuvers were completed. The background gas spectra obtained during the first Earth return of the spacecraft showed peaks of $\mathrm{He}, \mathrm{Ar}$, 


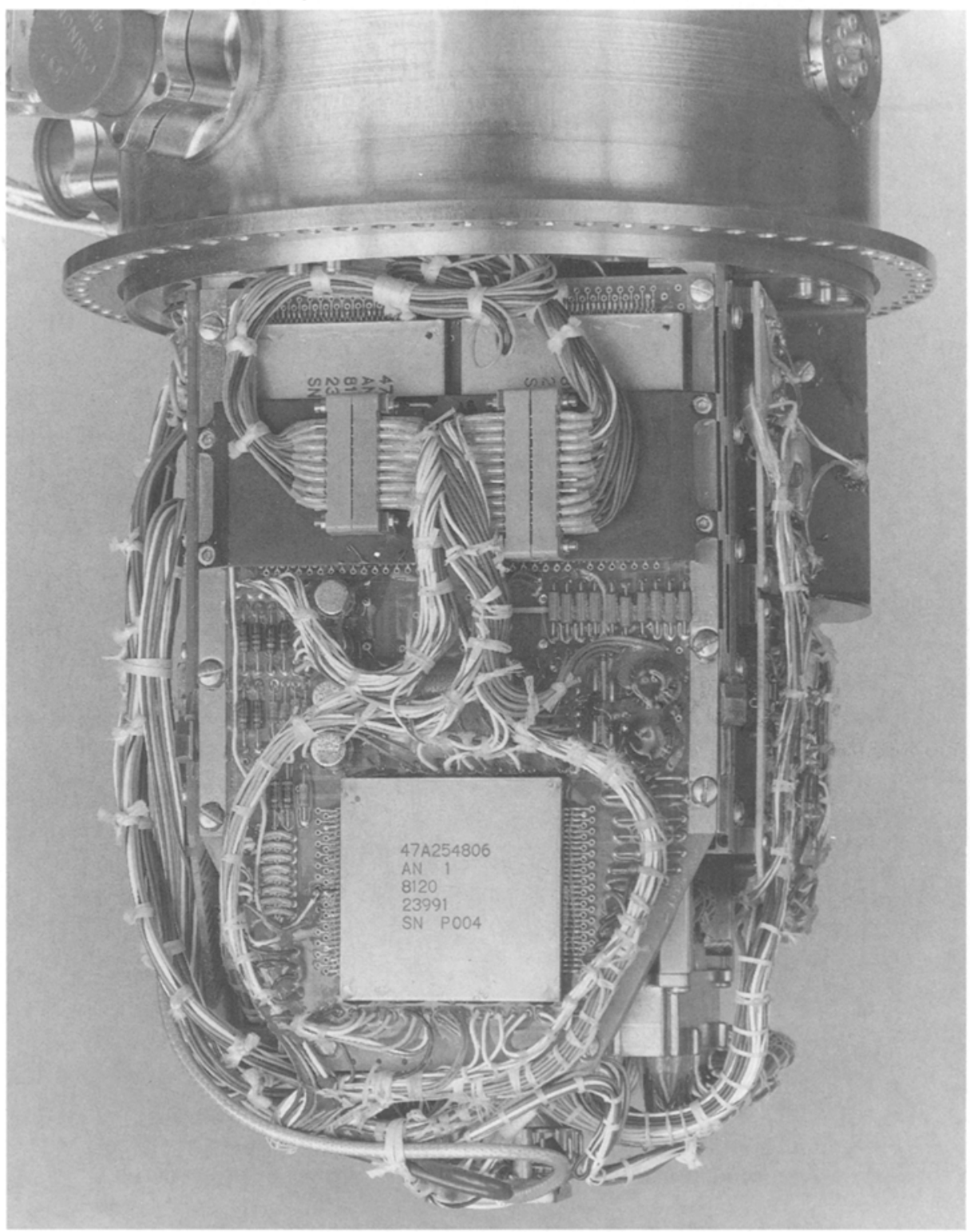

Fig. 7. Electronics System Assembly of the Galileo Probe Mass Spectrometer.

$\mathrm{CH}_{4}, \mathrm{H}_{2} \mathrm{O}, \mathrm{CO}$, and $\mathrm{CO}_{2}$. Helium, argon and methane background pressures seen at the instant of turn on were $1 \times 10^{-9} \mathrm{mbar}, 2 \times 10^{-9} \mathrm{mbar}$, and $2 \times 10^{-12} \mathrm{mbar}$, respectively. This background was removed within several seconds by the sputter ion pump leaving a residual pressure of $1 \times 10^{-12} \mathrm{mbar}$ for $\mathrm{CH}_{4}$ and $\mathrm{CO}_{2}, 3 \times 10^{-12} \mathrm{mbar}$ for $\mathrm{H}_{2} \mathrm{O}$ and less than $2 \times 10^{-13} \mathrm{mbar}$ for $\mathrm{He}, \mathrm{Ar}$, and $\mathrm{CO}$. 


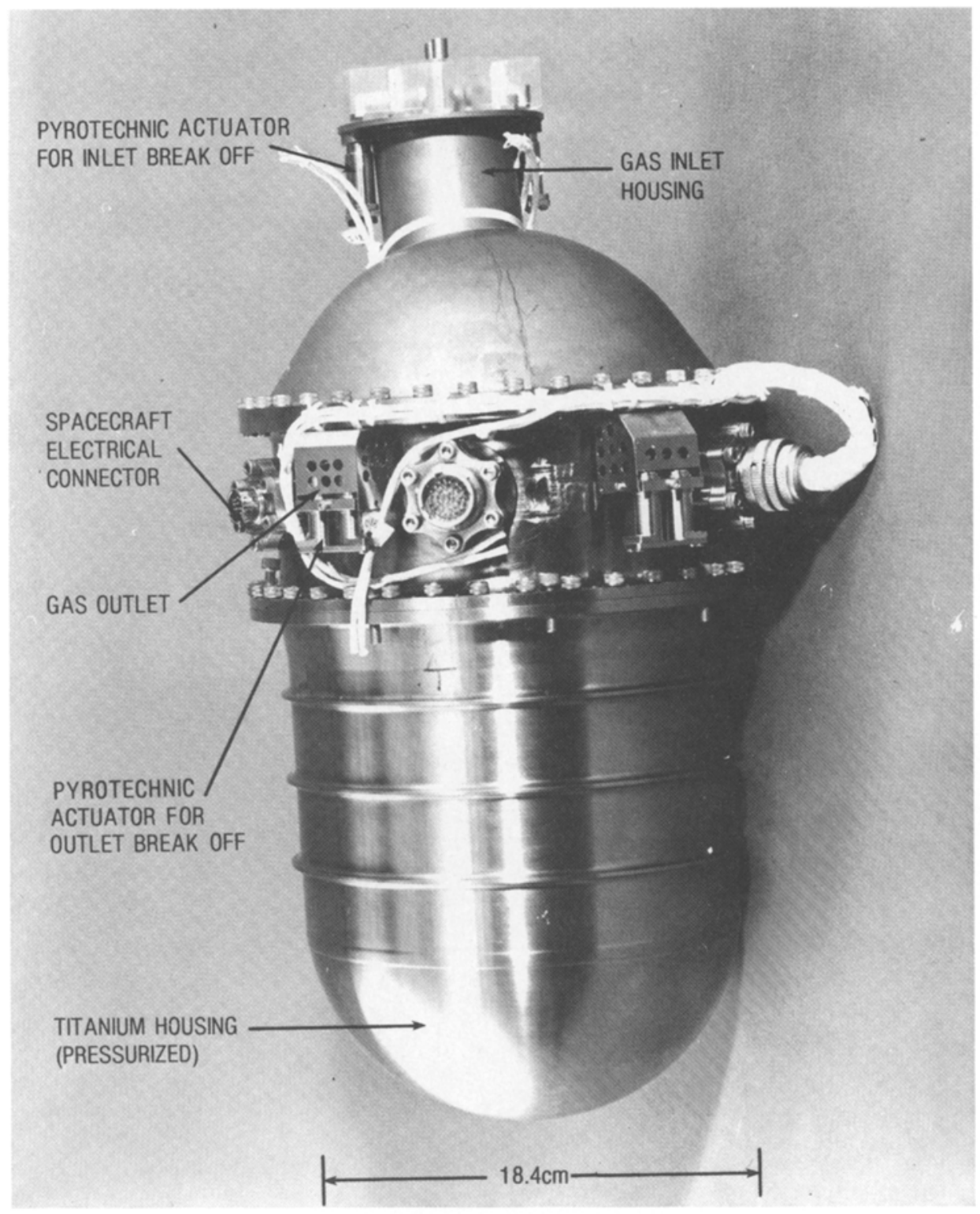

Fig. 8. Fully assembled Galileo Probe Mass Spectrometer.

For the remaining cruise time the instrument will be turned on once a year to operate the sputter ion pump for removal of noble gases, e.g., Ar, resulting from possible sudden release from gas pockets which may exist in the metal surfaces and welds. It is also necessary to exercise the micro valves, the only devices in the instrument containing moving parts, to prevent sticking under ultra high vacuum conditions. Since sticking in 
the closed position after long storage is the most likely failure mode of the valves, all valves are kept in the open position during the cruise phase of the mission.

Component redundancy is implemented in spacecraft support systems, but is usually not permitted in scientific instruments because of weight, size, power, and cost constraints. Hence, many single point failure possibilities exist in the instrument. Redundancy is provided, however, for the filaments because of the limited lifetime; for the pyrotechnic devices because of possible misfire; and for the isolation of inlet leak 1 by using two micro valves in series V10A and V10B because of catastrophic pressure increase in the ion source which would occur if the flow through leak 1 is not stopped at the designated closing time. The life expectancy of the electronic components in space is usually very high except for those which are radiation sensitive, e.g., microprocessors which are not part of our design.

The sampling sequence for the nominal one hour descent time was programmed on read only memory (ROM). Programs could be changed or corrected on the ground by substituting ROM units in the instrument but it remains fixed in flight. This approach avoided risks of radiation damage when using programmable onboard memory for which radiation hardened parts were not available.

\section{Laboratory Calibration of the Instrument}

Accurate instrument calibration is required for quantitative composition measurements in the atmosphere. The transfer characteristics of mass spectrometers depend on the species to be measured. Factors which affect signal levels include the ionization cross section, the effective pumping speed of the vacuum pumps, and the conversion efficiency and pulse height distribution of the secondary electron multiplier.

The instrument was calibrated on a dynamic flow system where the time, pressure, and temperature profile to be encountered during the Probe descent was simulated. Gas mixtures containing known mixing ratios of gases expected in the atmosphere of Jupiter were introduced into the high pressure flow system connected to the sample inlet system of the flight instrument. Ultra-pure, commercially available gas mixtures were used. To establish mixing ratios representative of the atmosphere of Jupiter those mixtures were further diluted with pure gases $\left(\mathrm{H}_{2}\right.$ and $\left.\mathrm{He}\right)$. The final mixing ratios of the minor constituents was checked or verified by a laboratory gas chromatograph mass spectrometer system as well as a stand-alone gas chromatograph and mass spectrometer. The design of the sample inlet system allowed complete and separate instrument calibration of all components used in flight except for the replacement of getter materials and the sputter ion pump. This was required after calibration to assure that maximum pump capacities are available for the experiment. All pumps on the flight instrument are designed to operate in a conductance limited mode so that small variations in pumping speed of the getter materials have a negligible effect on the instrument transfer function.

The calibration system consists of two parts, the high-pressure gas flow and sample mixing system, and the ultra-high vacuum pumping stand. A schematic diagram of the high pressure flow system is shown in Figure 9. Calibration gas mixtures are circulated 

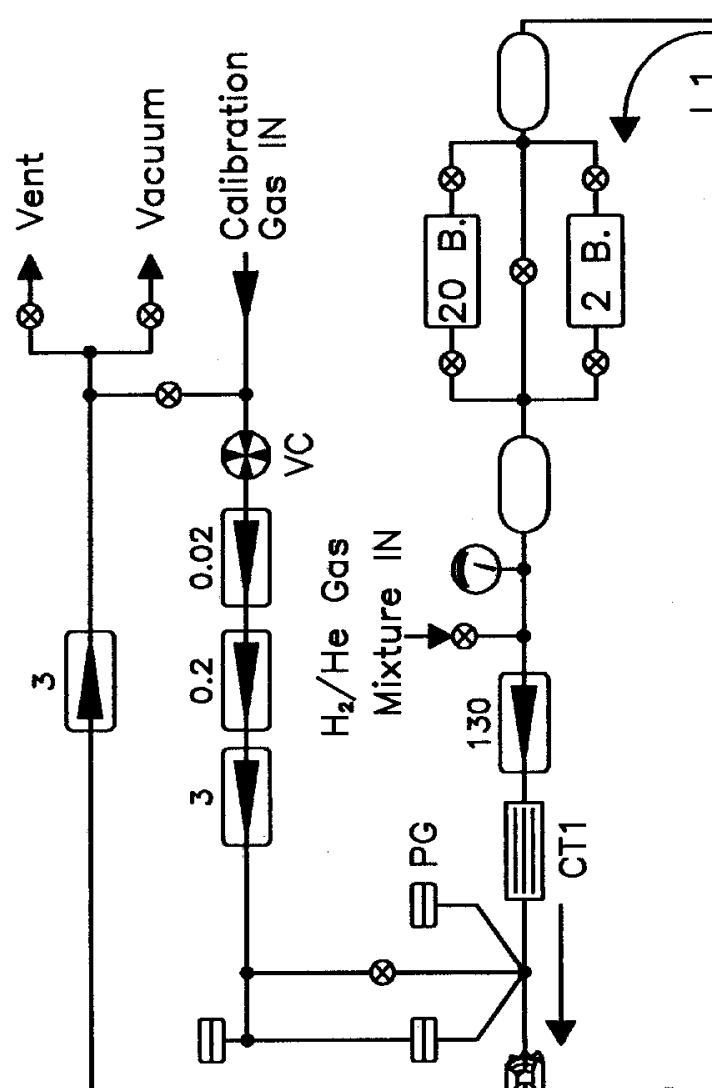

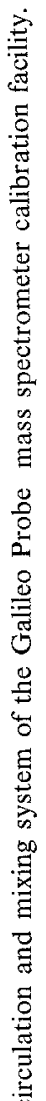
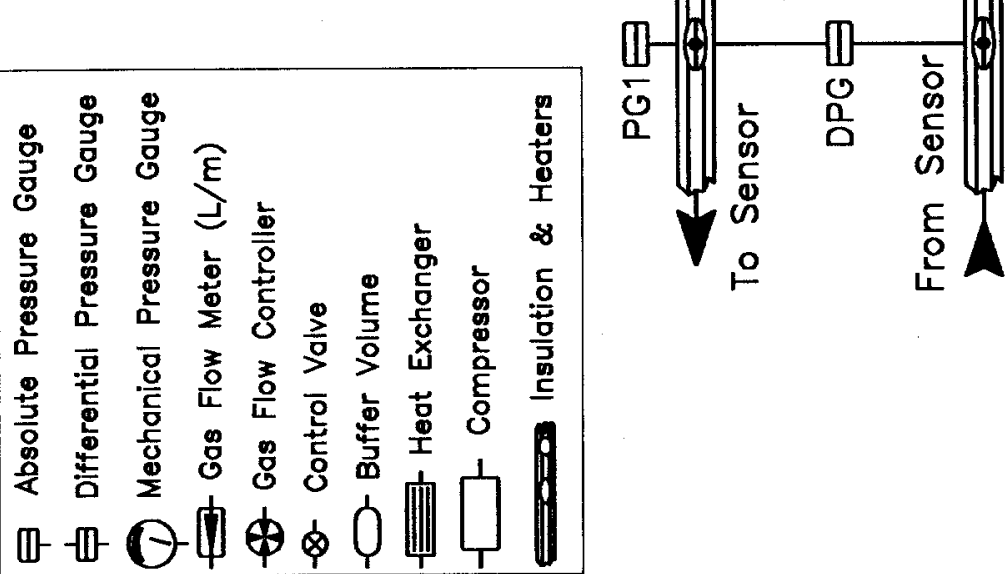
through loop L1 in the direction shown by the arrows. Two gas compressors are available for alternate use for gas compression and circulation through the circulating loop. They operate over the pressure range from 10 mbar to 2 bar and 1.0 to 20 bar. The flight instrument inlets and outlets were connected directly with vacuum flanges to the appropriate terminals as indicated in the schematic on the left side of Figure 9. All lines are thermally insulated and the gas temperature was controlled by heaters attached to the flow lines and heat exchangers CT1 and CT2 to heat or cool the circulating gas mixture as required. Absolute system pressure was monitored with pressure gauge PG1 and the differential pressure across the inlet was monitored with gauge DPG. The flow was adjusted so that the differential pressure was always equal to the Probe stagnation pressure (6 mbar) expected in flight. Trace gas mixtures were added in known quantities through the calibration gas line and valve VC. The exact quantities of added calibration gas was determined by measuring the gas flow with the flow meters and the pressure at the injection port with the pressure gauge $P G$.

The ultra-high vacuum pumping system was connected to the flight instrument through pumpout ports for evacuation, bake out at $\sim 300^{\circ} \mathrm{C}$ and getter pump activation. This is needed before calibration can begin and between calibration runs for getter reactivation and final instrument preparation for flight. Oil-free turbomolecular pumps and a closed circuit liquid helium pump provided the pumping capacity and ultra-high vacuum capability needed for thorough and rapid evacuation of the flight instrument system. Typical background pressures in the instrument, before calibration gases were introduced, were between $5 \times 10^{-11} \mathrm{mbar}$ and $2 \times 10^{-10} \mathrm{mbar}$ where the major component was $\mathrm{H}_{2}$ followed by $\mathrm{H}_{2} \mathrm{O}, \mathrm{CO}$, and $\mathrm{CO}_{2}$.

Detailed calibration was carried out with the gas mixtures containing primarily $\mathrm{H}_{2}$ and $\mathrm{He} 10 \%$ plus trace gases each at the 100 ppmv mixing ratio. A list of the calibration gases used either directly or in various combinations is given in Table VII. To establish

TABLE VII

Calibration gas mixtures

\begin{tabular}{lll}
\hline & Mixture & Inlet \\
\hline 1. & $\mathrm{H}_{2}+\mathrm{He}+\mathrm{Ne}+\mathrm{Ar}+\mathrm{Kr}+\mathrm{Xe}$ & 1,2 \\
2. & $\mathrm{H}_{2}+\mathrm{PH}_{3}$ & 1,2 \\
3. & $\mathrm{H}_{2}+\mathrm{HCN}$ & 1,2 \\
4. & $\mathrm{H}_{2}+\mathrm{H}_{2} \mathrm{~S}$ & 1,2 \\
5. & $\mathrm{H}_{2}+\mathrm{He}+\mathrm{AsH}_{3}+\mathrm{SiH}_{4}+\mathrm{PH}_{3}$ & 1,2 \\
6. & $\mathrm{H}_{2}+\mathrm{He}+\mathrm{CH}_{4}+\mathrm{C}_{2} \mathrm{H}_{6}+\mathrm{C}_{3} \mathrm{H}_{8}$ & 2 \\
7. & $\mathrm{H}_{2}+\mathrm{C}_{2} \mathrm{H}_{2}+\mathrm{C}_{2} \mathrm{H}_{4}+\mathrm{C}_{3} \mathrm{H}_{6}$ & 2 \\
8. & $\mathrm{He}_{2}+\mathrm{H}_{2} \mathrm{O}$ & 2 \\
9. & $\mathrm{H}_{2}+\mathrm{He}+\mathrm{NH}_{3}$ & 2 \\
10. & $\mathrm{H}_{2}+\mathrm{He}+\mathrm{CH}_{4}+\mathrm{C}_{2} \mathrm{H}_{2}+\mathrm{C}_{2} \mathrm{H}_{4}+\mathrm{C}_{2} \mathrm{H}_{6}+\mathrm{C}_{3} \mathrm{H}_{6}+$ & 2 \\
& $+\mathrm{C}_{3} \mathrm{H}_{8}+\mathrm{C}_{4} \mathrm{H}_{10}+\mathrm{C}_{6} \mathrm{H}_{6}+\mathrm{C}_{6} \mathrm{H}_{12}$ & \\
\hline
\end{tabular}

Calibration gas mixture used to calibrate the GPMS. The mixture consisted of either $\mathrm{H}_{2}$ or $\mathrm{H}_{2} 90 \%$ and $\mathrm{He} 10 \%$ and trace gases as indicated each at the 100 to 150 ppmv mixing ratios. 
detailed relative sensitivities of the trace constituents with respect to $\mathrm{H}_{2}$ and $\mathrm{He}$ and to evaluate the fractionation pattern at the three energy levels of the ionizing electron beams, the gas mixtures were introduced into the sample inlet system without further dilution, i.e., with trace gas mixing ratios each of order of 100 ppmv but at several fixed pressure levels between 100 mbar and 20 bar. Finally the descent profile, i.e., pressure and temperature vs time was simulated in the high-pressure flow system exposing the flight instrument to flight-like operating conditions. Predicted pressure-time and temperature-time profiles shown in Figure 4(a) were approximated as closely as possible for that test. All calibration data were recorded and processed on automated data processing equipment using software generated during the instrument development phase.

Some concern has been expressed that the presence of hydrogen in the ion source might impede the measurement of isotope ratios. Tests of the noble gas mixture with and without added $\mathrm{H}_{2}$ at high ion source pressure, where hydride formation should be most pronounced, showed that the effect in flight will be too small to be observed. In addition, the purification cell efficiently removes the hydrogen and further alleviates any possible concern for the measurement of noble gas isotope ratios. This system shows great promise for the measurement of helium-3. An example of this is given in the graphic illustration shown in Figure 10 for $\mathrm{H}_{2}$ and $\mathrm{He}$. The purification permits the ${ }^{3} \mathrm{He}$ isotope to be measured well above background. Tests also verified that the carbon isotope ratio measurement using the methane spectrum is not affected by hydride formation in the ion source as shown in Table VIII.

TABLE VIII

$\mathrm{CH}_{4}$-hydrides

\begin{tabular}{lllll} 
& Source pressure & & \multicolumn{3}{c}{ Fragmentation peaks } \\
\cline { 3 - 5 } & & 15 & 16 & 17 \\
\hline Pure & $\approx 2.0 \times 10^{-6} \mathrm{mb}$ & 0.767 & 1.0 & $1.01 \times 10^{-2}$ \\
$\mathrm{H}_{2}+\mathrm{CH}_{4}$ & $\approx 4.0 \times 10^{-6} \mathrm{mb}$ & 0.762 & 1.0 & $1.02 \times 10^{-2}$ \\
\hline
\end{tabular}

Normalized peak heights of methane at 15,16 , and $17 \mathrm{amu}$ of pure $\mathrm{CH}_{4}$ at $2.0 \times 10^{-6} \mathrm{mbar}$ ion source pressure and equal parts $\mathrm{H}_{2}$ and $\mathrm{CH}_{4}$ mixture at $4 \times 10^{-6} \mathrm{mbar}$ total ion source pressure indicating no measurable hydride formation in this pressure range.

Since it was not possible to calibrate the flight instrument with all the gases which might be found in the atmosphere of Jupiter and since the unambiguous interpretation of mass spectra obtained in flight can be difficult, a laboratory reference unit has been built. The engineering unit instrument was refurbished to be identical to the flight instrument. Post encounter simulations of flight results are planned using the laboratory unit and the calibration system to further aid in the data interpretation by reproducing experimentally as close as possible the data obtained in flight using various test gas mixtures. 


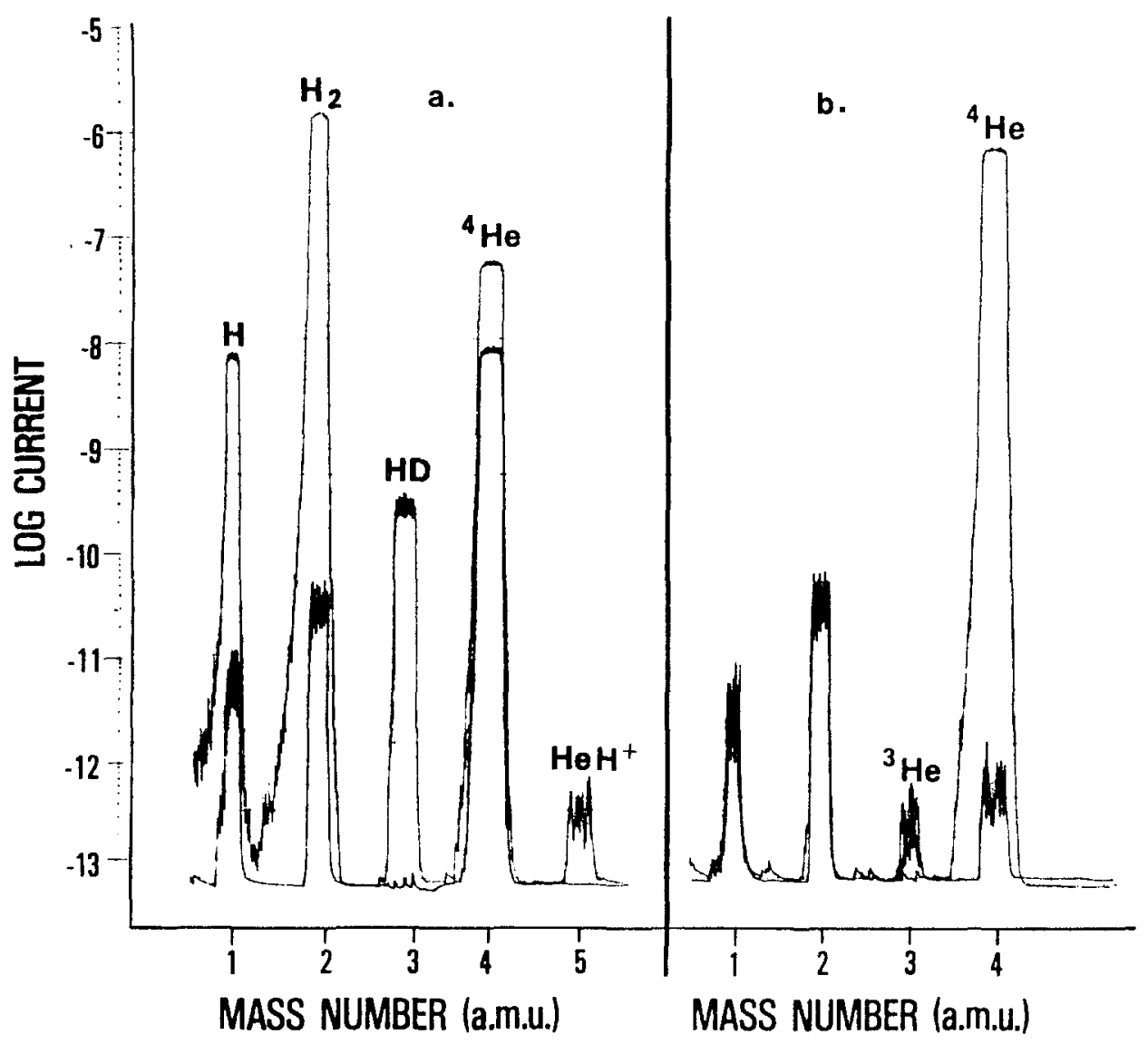

Fig. 10. Effect of purification cell on He isotope measurement. (a) Top spectrum shows a $90 \%$ hydrogen-10\% helium mixture through direct leak 2 at 3 bar inlet pressure. The bottom spectrum is the same mixture after the hydrogen has been removed by the getter to the background level. The helium decrease in the bottom spectrum is from the volume expansion in the getter volume. (b) Top spectrum is a pure helium sample through direct leak 2 at an inlet pressure of 3 bar. The bottom spectrum shows the background gases. The helium 3 level in this example is approximately $10^{-7}$ below the helium 4 level. For illustration the spectra were recorded analog with laboratory equipment introducing also extra system noise at low level signals.

\section{Expected Results and Measurement Accuracies}

The objective of this experiment, as stated above, is the measurement of the chemical composition of the atmosphere of Jupiter, i.e., the mixing ratio of the major and minor constituents during the Probe descent. The basic accuracy of the measurements and the detection limits of trace gases are determined by the sensitivity of the instrument, the maximum operating pressure of the ion source and the dynamic range of the mass spectrometer. The ion source sensitivity varies with species depending on the ionization cross sections, for example, the sensitivity is $1.6 \times 10^{13}$ counts per second mbar for molecular nitrogen, $2.2 \times 10^{12}$ counts per second mbar for helium and $8.9 \times 10^{12}$ counts per second mbar for hydrogen. The background count rate of the 
secondary electron multiplier ion detector is less than 0.1 counts per second. An ion source pressure of $2 \times 10^{-5}$ mbar will be reached at the end of the direct leak 1 and leak 2 measurement phases and during the enrichment cell analysis periods. The exact ion source pressure cannot, of course, be predicted since assumptions had to be made about the descent pressure-time profiles. A maximum ion source pressure of $1 \times 10^{-4}$ mbar is acceptable.

In the spectral regions where the maximum dynamic range of the instrument can be used, the accuracy will be limited by pulse counting statistics at low mixing ratios. At large mixing ratios where counting statistics become negligible, the measurement accuracy will be $\pm 2 \%$ for peak height ratio measurements of adjacent mass peaks and $\pm 10 \%$ for peak height ratios with wide mass separation. This is because of the error accumulation resulting from calibration uncertainties, small temperature drifts in the supply electronics and change in the gain of the secondary electron multiplier.

In the analysis of gas mixtures, ambiguities in species identification and additional accuracy limitations are expected for species with overlapping mass spectra. Some ambiguities will be resolved by using different energies for the ionizing electron beam. This will be effective for species with strongly differing ionization potentials and energy dependent ionization and dissociation cross sections. Space flight constraints of low weight, power, and volume put restrictions on the size of vacuum pumps and thus limiting the admissible sample size and the achievable background pressure. The available power for the RF generator for the quadrupole puts limits on the achievable mass resolution. The short descent time also restricts the chance for extensive signal averaging. This is particularly important for traces of reactive gases which may initially be absorbed or decomposed on the surfaces of the sample inlet system before they reach the ion source. Reactions of hydrogen with loosely bound carbon or oxygen on the vacuum surfaces in the ion source regions cause the formation of methane and water vapor. This effect was significantly suppressed by surface processing, e.g., carbon depletion and formation of stable surface oxides. Methane and water vapor buildup in a hydrogen atmosphere are, however, still limiting the measurement accuracy for these gases.

Early methane concentration measurements will therefore be most accurate, e.g., $\pm 10 \%$ at the expected mixing ratio of $10^{-4}$. Measurements made near the end of the mission are expected to be uncertain by a factor of two. Water vapor measurements in the mid pressure range $(\approx 7 \mathrm{bar})$ are expected to be also uncertain by a factor of two if the mixing ratio is $\approx 10^{-5}$. Better accuracies $( \pm 50 \%)$ are expected if the mixing ratios are close to solar values of $\approx 10^{-3}$. Other gases causing chemical noise are carbon monoxide, carbon dioxide, and ethane. Carbon monoxide and carbon dioxide form a constant background of several hundred counts per second which does not appear to change significantly when hydrogen enters the ion source. Ethane, on the other hand, does not occur in the background spectrum prior to exposure to hydrogen but it appears in small quantities of 1 ppmv levels when hydrogen enters the inlet. This background level can conceivably change in flight depending on its origin. If ethane is formed in a similar method as methane the background is expected to be the same as during the 
laboratory tests. Should ethane slowly accumulate on the vacuum surfaces and be desorbed when hydrogen is introduced, the ethane background could become larger or smaller depending on which process, outgassing or pumping, is dominating over the long time period of the cruise phase of the mission. The background level of ethane will ultimately determine the detection threshold of gases with similar fragmentation patterns such as silane, ethylene, and acetylene.

No background gases or chemical noise is expected above mass 44 at high ion source pressures and hence constituent measurement accuracies in this region are expected to be determined by the statistical uncertainties associated with the respective sampling times at low concentrations or by the uncertainties caused by temperature drift, etc., to $\pm 10 \%$ as stated above at large concentration levels. Examples of gases which will be detected in this higher, chemically cleaner mass range are krypton, xenon, arsine, and the higher molecular weight hydrocarbons.

Reactive trace gases of particular interest which are affected by surface adsorption or reactions are ammonia $\left(\mathrm{NH}_{3}\right)$, hydrogen sulfide $\left(\mathrm{H}_{2} \mathrm{~S}\right)$, and phosphine $\left(\mathrm{PH}_{3}\right)$. All three gases are transmitted without delay or apparent surface loss through inlet 2 because of the direct gas beaming feature of the ion source. Ammonia, the most reactive gas of the set, will not be transmitted to the ion source from leak 1 at a mixing ratio of $\approx 10^{-5}$ in any reasonable amount of time for a measurement. Evaporating cloud droplets are expected to be detectable, however, although quantitative calibration was not possible because of lack of time and facilities to produce droplets in known quantities during the calibration and evaluation period. Spectral interference with methane at mass $17\left({ }^{13} \mathrm{CH}_{4}\right)$ will limit the detection threshold of ammonia through leak 2 to a mixing ratio of approximately $10^{-5}$ (equal signal from ammonia and methane). Hydrogen sulfide is measurable through inlet 1 after a few seconds delay depending on the mixing ratio. At the predicted mixing ratio of $\approx 10^{-5}$ we expect a $\pm 50 \%$ accuracy of the measurement. Transmission of phosphine was observed without any noticeable delays and the measurement accuracy will be primarily affected by spectral interference at the parent peak from hydrogen sulfide. Phosphine can be measured, however, by observing the mass 31 peak which occurs with an intensity of 0.25 of the parent peak and is free from spectral interference except from ethane $\left({ }^{13} \mathrm{C}^{12} \mathrm{CH}_{6}\right)$. Assuming the predicted composition and carbon isotope ratio of ethane, the phosphine mixing ratio will be determined at least to a factor of two at the $10^{-7}$ mixing ratio. Enrichment factors of 100 are expected for ethane and propane and of 500 for higher order hydrocarbons. Krypton and xenon will be enriched approximately 10 times and 100 times, respectively. The actual accuracies can only be established after the data are received and analyzed, because the spectral interference depends on the actual data and background gas uncertainties resulting from the long storage and cruise time.

\section{Sampling Sequence Summary}

A brief description of the sampling sequence which will be followed by the instrument during the entry phase is given below. 
The instrument contains an unalterably programmed 8192 step sampling sequence designed to optimize the data return at a sampling rate of two steps per second. The SEQUENCE START command is sent from the Probe Command and Data System to the instrument after the Probe parachute has been deployed and the heat shield has been jettisoned. All reference times quoted are with respect to the SEQUENCE START command. The ambient pressure values were taken from the engineering pressures vs. descent time model provided by the Galileo Project. After an automatic self-configuration which includes setting valves and heaters in the proper positions for the operations that follow, the instrument measurement sequence begins at $t=1.97 \mathrm{~min}, P \approx 0.1 \mathrm{bar}$ by monitoring the 'residual' gas content (background).

\section{Photochemical Sampling}

Inlet 1 and Outlet 1 open at $t=2.66 \mathrm{~min}, P \approx 0.15$ bar to expose the first gas handling system to the ambient atmosphere. The atmosphere will be sampled in seven sequences where data corresponding to masses $2-4,12-68,72-78,80-84,122$, and 124 amu are transmitted.

\section{$\mathrm{NH}_{3}$ Cloud Sampling}

In the region where ammonia $\left(\mathrm{NH}_{3}\right)$ cloud are predicted, $t=6.70 \mathrm{~min}, P \approx 0.7$ bar, the mass range from 2 to 150 is scanned seven times. Approximately every $30 \mathrm{~s}$ $(\Delta P=0.1$ bar), the scan is interrupted to repeat the measurements at masses $14-18$, 32-36, 64, and 66 amu.

\section{Filling of Enrichment Cell 1 and Rare Gas Cell}

During direct sampling in the photochemical region, the enrichment cell $\mathrm{Cl}$ is exposed to the ambient atmosphere; $t=4.71 \mathrm{~min}, P \approx 0.4$ bar until $t=13.05 \mathrm{~min}, P \approx 1.9$ bar. After isolation of the cell from the ambient atmosphere, gases not trapped by the sorbent material of the cell are expanded into the rare gas cell; $t=13.12 \mathrm{~min}$ to $t=16.10 \mathrm{~min}$.

\section{Background Gas Observation}

At time $t=17.06 \mathrm{~min}$ the instrument inlet system is closed to allow observation of background gases accumulated during the measurement phase. The baseline condition is monitored by executing two decremental integer mass sweeps over the range of 150 to $2 \mathrm{amu}$ and four measurements in the $0.125 \mathrm{amu}$ mass incremental mode at masses $28,44,16$, and 4 amu.

\section{Rare Gas Sampling}

The rare gas cell content is analyzed from $t=19.98 \mathrm{~min}$ to $t=22.40 \mathrm{~min}$ in six sequences. The first and last sequences include mass sweeps over the range 2-28 amu plus those masses corresponding to the isotopes of $\mathrm{Kr}$ and $\mathrm{Xe}$. The other sequences monitor those masses corresponding to the isotopes of $\mathrm{He}, \mathrm{Ne}, \mathrm{Ar}, \mathrm{Kr}$, and $\mathrm{Xe}$. To separate $\mathrm{Ne}$ from $\mathrm{Ar}^{++}$several scans are made at an ionization energy of $25 \mathrm{eV}$. 


\section{Rare Gas and First Enrichment Cell Sampling}

At $t=22.40 \mathrm{~min}$ the enrichment cell $\mathrm{C} 1$ processed sample from the enrichment cell is added to the rare gas cell sample for analysis. Four sequences are performed: 3 sweeps of the mass range 2-150 amu, and 1 covering masses 2-87 amu and 123-137 amu. An ionization energy of $15 \mathrm{eV}$ is used during one full mass scan.

\section{Background Gas Observation}

After the enrichment cell analysis the cell is sealed off and the analyzer is pumped down to background pressure. At $t=27.78 \mathrm{~min}$ the instrument program executes three sequences where the background gas content is recorded once more after the enrichment cell analysis. Two mass scans cover the mass range 150-2 amu while the third mass scan covers masses $68-2$ amu.

\section{Direct Atmospheric Sampling}

The second gas inlet system is opened to the ambient atmosphere starting at $t=30.99 \mathrm{~min}, P \approx 7.0 \mathrm{bar}$ and remains open until the end of the mission. Thirty-one sampling sequences are performed, twenty covering the mass range 2-150 amu, two scan the 2-68 amu region while the other nine monitor selected masses. Selected scans are also programmed for ionization energies of either $15 \mathrm{eV}$ or $25 \mathrm{eV}$.

\section{Filling of Enrichment Cell 2 and Analysis}

While sampling the atmosphere directly, enrichment cell $\mathrm{C} 2$ will be filled from time $t=31.68 \mathrm{~min}$ to time $t=33.27 \mathrm{~min}$ corresponding to a predicted pressure range from $P \approx 7.3$ to 7.8 bar. Following the isolation of the cell from the gas handling system, sample processing begins. The sample analysis will start at $t=38.99 \mathrm{~min}$ and end at $t=46.40 \mathrm{~min}$. The predicted pressure levels are $P \approx 10.0$ to $13.0 \mathrm{bar}$, respectively. During this time, five scans covering the mass range from 2-150 amu are performed. The ionization energies chosen for these scans is $75,15,75,25$, and $75 \mathrm{eV}$.

\section{High-Mass Resolution Scan}

A high-resolution mass scan for selected mass ranges $(2-46,47-90,121-140) \mathrm{amu}$ is performed at $t=48.97 \mathrm{~min}, P \approx 14.0$ bar. During this scan, a mass step size of $0.125 \mathrm{amu}$ is used.

\section{End of Mission Sequence}

At the completion of the High-Mass Resolution Scan at $t=59 \mathrm{~min}, P \approx 19.0$ bar, the instrument will begin repeating a $2-150 \mathrm{amu}$ scan every $75 \mathrm{~s}$ until the end of mission.

\section{Acknowledgements}

The dedication and efforts of many people made this complex and difficult experiment possible. The authors and the Experimenter Team wish to acknowledge particularly the 
contributions at Goddard Space Flight Center of J, Cooley for the excellent work as Instrument Manager and S. Way for his excellent support for the electronics system development and the hybrid fabrication.

Others at Goddard deserving thanks are R. Abell, R. Arvey, H. Benton, A. Doan, J. Fedor, J. Haberman, R. Lott, P. Mahaffy, H. Mende, H. Powers, J. Richards, T. Tyler, and J. Westberg of the instrument development team, J. Milligan, leader of the systems review team, and G. Peters for support in quality assurance.

At the University of Michigan we thank the electronics system development team of Bruce Block, J. Maurer, J. Caldwell and W. Pinkus and J. Eder for his support of the quality assurance program.

At the General Electric Co. we thank V. Geracy, L. Milton and their team members for the hybrid circuit fabrication.

At NASA Ames Research Center we thank the Galileo Probe Project Office for their support and guidance in this program. In particular we are indebted to A. Wilhelmi for his considerable effort as technical coordinator between the Project and the Experimenter Team. Last but not least the very capable management provided by $\mathbf{J}$. Sperans, E. Tischler, and B. Chin is gratefully acknowledged.

\section{References}

Anders, E. and Grevesse, N.: 1989, Geochim Cosmochim. Acta 53, 197.

Atreya, S. K.: 1986, Atmospheres and Ionospheres of the Outer Planets and Their Satellites, Chapter 1, Springer-Verlag, New York.

Atreya, S. K. and Romain, P. N.: 1985, in G. E. Hunt (ed.), 'Photochemistry and Clouds of Jupiter, Saturn and Uranus', Planetary Meteorology, Cambridge University Press, Cambridge, p. 17.

Bar-Nun, A., Dror, J., Kochavi, E., and Laufer, D.: 1988, Phys. Rev. B35, 2427.

Bjoraker, G. L., Larson, H. P., and Kunde, V. G.: 1986, Astrophys. J. 311, 1058.

Carlson, B. E., Lacis, A. A., and Rossow, W. B.: 1991, Astrophys. J. (in press).

Dawson, P. (ed.): 1976, Quadrupole Mass Spectrometry and Its Applications, Elsevier Scientific Publ. Co., New York.

Gautier, D. and Owen, T.: 1983, Nature 302, 215.

Gautier, D. and Owen, T.: 1989, in S. K. Atreya, J. B. Pollack, and M. S. Mathews (eds.), Origin and Evolution of Planetary and Satellite Atmospheres, University of Arizona Press, Tucson, p. 487.

Geiss, J. and Bochsler, P.: 1982, Geochim. Cosmochim. Acta 46, 529.

Geiss, J. and Reeves, H.: 1981, Astron. Astrophys. 93, 189.

Kerridge, J. F.: 1989, Science 245, 480.

Larson, H. P., Davis, D. S., Hoffman, R., and Bjoraker, G. L.: 1984, Icarus 60, 621.

Lunine, J. I. and Hunten, D. M.: 1987, Icarus 69, 566.

Lunine, J. I. and Stevenson, D. J.: 1985, Astrophys. J. Suppl. 58, 493.

Nier, A. O. C. and McElroy, M. B.: 1977, J. Geophys. Res. 82, 4341.

Noll, K. S., Knacke, R. F., Geballe, T. R., and Tokunaga, A. T.: 1988, Icarus 75, 409.

Noll, K. S., Gaballe, T. R., and Knacke, R. F.: 1989, Astrophys. J. 338, L71.

Noll, K. S., Larson, H. P., and Geballe, T. R.: 1990, Icarus 83, 494.

Paul, W. and Steinwedel, H.: 1953, Naturforschung A8, 448.

Paul, W., Reinhard, H. P., and von Zahn, U.: 1958, Phys. 152, 143.

von Zahn, U. and Hunten, D. M.: 1992, Space Sci. Rev. 60, 263 (this issue).

Widenschilling, S. J. and Lewis, J. S.: 1973, Icarus 20, 465. 